\title{
Article \\ Combining Object-Based Machine Learning with Long-Term Time-Series Analysis for Informal Settlement Identification
}

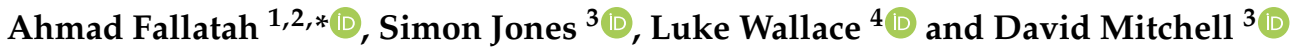 \\ 1 Department of Geomatics, Faculty of Architecture and Planning, King Abdulaziz University, \\ Jeddah 21589, Saudi Arabia \\ 2 The Center of Excellence in Smart Environment Research, King Abdulaziz University, Jeddah 21589, \\ Saudi Arabia \\ 3 School of Science, RMIT University, Melbourne, VIC 3000, Australia; simon.jones@rmit.edu.au (S.J.); \\ david.mitchell@rmit.edu.au (D.M.) \\ 4 School of Geography, Planning and Spatial Sciences, University of Tasmania, Hobart, TAS 7005, Australia; \\ luke.wallace@utas.edu.au \\ * Correspondence: amfallatah@kau.edu.sa; Tel.: +966-506622399
}

check for updates

Citation: Fallatah, A.; Jones, S.; Wallace, L.; Mitchell, D. Combining Object-Based Machine Learning with Long-Term Time-Series Analysis for Informal Settlement Identification. Remote Sens. 2022, 14, 1226. https:// doi.org/10.3390/rs14051226

Academic Editor: Saeid Homayouni

Received: 29 December 2021

Accepted: 23 February 2022

Published: 2 March 2022

Publisher's Note: MDPI stays neutral with regard to jurisdictional claims in published maps and institutional affiliations.

Copyright: (C) 2022 by the authors. Licensee MDPI, Basel, Switzerland. This article is an open access article distributed under the terms and conditions of the Creative Commons Attribution (CC BY) license (https:// creativecommons.org/licenses/by/ $4.0 /)$

\begin{abstract}
Informal settlement mapping is essential for planning, as well as resource and utility management. Developing efficient ways of determining the properties of informal settlements (when, where, and who) is critical for upgrading services and planning. Remote sensing data are increasingly used to understand built environments. In this study, we combine two sources of data, very-highresolution imagery and time-series Landsat data, to identify and describe informal settlements. The indicators characterising informal settlements were grouped into four different spatial and temporal levels: environment, settlement, object and time. These indicators were then used in an object-based machine learning (ML) workflow to identify informal settlements. The proposed method had a $95 \%$ overall accuracy at mapping informal settlements. Among the spatial and temporal levels examined, the contribution of the settlement level indicators was most significant in the ML model, followed by the object-level indicators. Whilst the temporal level did not contribute greatly to the classification of informal settlements, it provided a way of understanding when the settlements were formed. The adaptation of this method would allow the combination of a wide-ranging and diverse group of indicators in a comprehensive ML framework.
\end{abstract}

Keywords: informal settlement indicators; urbanisation; sustainable development goals (SDGs); machine learning (ML); very-high-resolution (VHR); time-series analysis; object-based image analysis (OBIA)

\section{Introduction}

For many of the world's urban poor, slums and informal settlements have become the new reality. Informal settlements are the result of a pressing demand for shelter, rapid urbanisation, and a scarcity of acceptable housing [1,2]. The term "informal settlement", as used in this paper, has a wide-ranging meaning, incorporating slums but also referring to other unplanned settlements not authorised by local authorities. Providing timely and accurate spatial information about informal settlements is essential. This information can help to facilitate enhanced urban planning and service provision, as well as helping to ameliorate social and environmental issues [3,4].

Because signatory countries will be expected to report their progress towards sustainable development goals, the 2030 Agenda for Sustainable Development serves as a planning framework for informal settlements (SDGs) [2]. Sustainable Development Goal 11.1.1 includes a series of aims pertinent to issues surrounding informal settlements, to be met by 2030 [5]. Ending poverty and hunger, combatting inequities, preserving human rights, promoting gender equality, and establishing conditions for long-term, inclusive, and sustainable economic growth are among the targets [6]. Through the reduction (by 
at least half) in the number of people living in poverty and providing appropriate, safe, and affordable housing, as well as essential services, including the upgrading of slums, the 2030 agenda aims to improve the living conditions of informal settlement residents. While evidence of a steady shift in poverty from rural to urban regions is developing, it is obvious that updated data on urbanisation, especially the spread of informal settlements, is required [7].

\subsection{Spatial Data}

High-quality urban data for use as a fact foundation are critical to decision-making at multiple scales, and across a wide range of sectors. Non-governmental organizations and researchers in developing nations, in particular, typically have difficulty accessing these data [8]. In order to manage urban development and urban growth, spatial and attribute data are essential requirements for establishing policies, urban studies, and future planning [9]. Many approaches were proposed to evaluate urban growth and sprawl $[10,11]$. High amounts of geographical and temporal resolution data are required to understand the dynamics of land-change processes in metropolitan settings [12]. Remote sensing data sets are useful due to their synoptic view, recurring coverage and real-time data collection [13].

The spatio-temporal analysis of satellite images gives significant information regarding changes in land cover and land use (LCLUC) [14,15]. The growing volume and accessibility of remote sensing data has inspired several new methods for mapping key environmental features and processes [16]. For example, using timeseries satellite images to identify changes in forest cover and LCLUC is one of numerous viable but extremely variable approaches $[17,18]$. Monitoring land changes is anticipated to provide useful data for regional informal settlement management and planning, as well as a better understanding of the underlying socioeconomic and biophysical mechanisms affecting observable land changes in urban settings $[18,19]$.

\subsection{Object-Based Approaches for Informal Settlement Mapping}

In terms of definitions, types, data availability, and procedures, monitoring informal settlements from satellite images is challenging [20]. Object-based image analysis (OBIA) approaches to classifying satellite imagery have demonstrated strong capability for overcoming some of these challenges when compared with pixel-based algorithms for urban identification [21]. OBIA methods can be applied to extract urban impervious surfaces using a range of feature descriptors, including textural, spectral, semantic, topological, and geometric information [22]. For object attribution, OBIA has the potential to capture heterogeneity utilizing contextual information and local knowledge [23]. OBIA approaches have been tested for distinguishing formal from informal settlements in different environments and at multiple scales [24-27].

In addition to base satellite images, combining OBIA with machine learning (ML) classification algorithms enables the inclusion of geographical and other auxiliary data. The utility of OBIA and the random forest ML algorithm was tested by [28] using physical characteristics (i.e., slope) and remote-sensing-derived descriptors, providing a classification accuracy of $91 \%$ for informal settlement mapping from GeoEye-1 imagery. In recent works [4,17], the authors showed that ML algorithms have the highest reported accuracies in comparison to manually created rulesets and pixel-based approaches. ML-based classifications also allow a broad set of indicators to be evaluated in a computationally efficient manner. The random forest algorithm has become a good candidate for different remote-sensing classification tasks using different data sources [28-35].

\subsection{Monitoring Urban Change in Informal Settlements}

Time-series analysis (TSA) is essential for the attribution of disturbance types and land cover classes, especially for urban areas [36]. Many machine learning algorithms have been applied to quantify LCLUC [37]. These algorithms have been developed to deal with the monitoring of forest change over large geographic areas [38]. However, there is 
significant potential to test the utility of such algorithms in urban areas to better understand the creation of informal settlements over time. There are many advantages to the adoption of TSA approaches to detect changes and to map informal settlements. TSA is capable of handling short-duration events and long, smooth trends. It is able to illustrate changes and their duration, as well as when exactly they occur and their magnitude. First, the problem of informal settlements is highly associated with developing countries. Second, the whole historic Landsat archive held by the USGS is now freely available online in highly pre-processed formats [39]. Therefore, there has been a significant growth in the usage of Landsat data by many areas of society [36]. Third, [40] developed, evaluated, and operationalised powerful automated algorithms capable of processing annual LTS. One of the algorithm's features is its sample design flexibility, specifically the ability to sample an area of interest with statistical validity over space and time [40].

Rapid population growth in developing countries mostly affects metropolitan cities, causing dynamics in LCLUC that mostly result in a decrease in natural resources [14]. There is a huge demand for detailed information on urban transformation across large areas that is both temporally and spatially detailed, as well as for urban management and policy features [41]. LandsatLinkr has been used to detect forest dynamics over large areas using Landsat [35,42]. Furthermore, it has been used in urban applications, such as surface temperature [43], depending on biophysical land surface components, and tourism activities [14].

\subsection{Objectives}

Mapping heterogeneous objects throughout a large urban area is a time-consuming and challenging task $[43,44]$. While OBIA and machine learning algorithms can produce accurate maps of informal settlements from a single extremely-high-resolution image, the integration of TSA into this process is yet to be properly investigated and validated. Previous research has tended to concentrate on a limited number of images rather than taking into consideration the temporal information obtained by Landsat sensors [43]. This research investigates how the TSA technique, combined with a single-date, very-highresolution (VHR) image, could be utilised to map informal settlements in the Middle Eastern environment. The authors of [28] provide an overview of the indicators and parameters that were used to map and monitor informal settlements at the object, settlement, and environ levels. Therefore, in this research, we integrate two sources of data to map and monitor informal settlements: very-high-resolution imagery and time-series Landsat data. The informal settlements were identified using indicators that were extracted from the data and grouped into four different spatial and temporal levels: environment, settlement, object, and temporal. Table 1 shows the indicators used to map the informal settlements at the object, settlement, environment, and temporal levels to produce an informal settlement ontology. This was achieved through an object-based ML approach, in which features from these two data sources were mapped onto the ontological classes proposed in [45]. These indicators were then used in an object-based machine learning (ML) workflow to identify the informal settlements. Finally, the contribution of each class to the mapping of the informal settlements was evaluated and discussed. 
Table 1. The indicators of informal settlements considered in this study including temporal level as a new dimensional level to informal settlement mapping (adapted from [46]). For full details of the parameters and indices used for mapping informal settlements, see [25,28].

\begin{tabular}{|c|c|c|}
\hline Indicator & Description and Expected Informal Settlement Values & Level \\
\hline Roofing extent of built-up area & $\begin{array}{l}\text { The total area occupied covered by buildings. High densities are } \\
\text { expected in urban settlements. }\end{array}$ & Object \\
\hline Dwelling size & $\begin{array}{c}\text { Mean dwelling size. Small dwellings (between }<50 \mathrm{~m}^{2} \text { and } 380 \mathrm{~m}^{2} \text { ) } \\
\text { are expected in informal settlements. }\end{array}$ & Object \\
\hline Vegetation extent & $\begin{array}{l}\text { Total area covered by vegetation present. Low densities are } \\
\text { expected in urban settlements. }\end{array}$ & Settlement \\
\hline Lacunarity of housing structures & $\begin{array}{l}\text { Measures heterogeneity or 'gappiness' of empty spaces (lacunae) } \\
\text { between built-up structures. Low value expected. }\end{array}$ & Settlement \\
\hline Road segment type and materials & $\begin{array}{l}\text { Length and type of road segments. Less road elongation and fewer } \\
\text { regular road segments are expected in informal settlements. }\end{array}$ & Settlement \\
\hline Texture measures of built-up area & $\begin{array}{l}\text { Measurement of the arrangement of colour and within an area. } \\
\text { Less-structured and rapid changes expected in urban settlements. }\end{array}$ & Settlement \\
\hline Road accessibility & $\begin{array}{l}\text { Accessibility of roads for a range of vehicle types. Narrower roads } \\
\text { less suitable for vehicular traffic; a higher proportion of dead-ends } \\
\text { (dangles) and fewer intersecting nodes expected in } \\
\text { informal settlements. }\end{array}$ & Settlement \\
\hline Consistency of housing orientation & $\begin{array}{c}\text { Consistency in orientation of the directions of line segments } \\
\text { describing buildings. Low consistency expected in } \\
\text { informal settlements. }\end{array}$ & Settlement \\
\hline Dwelling shape & $\begin{array}{l}\text { The height and shape of dwellings, including the simplicity of } \\
\text { shape (four-sidedness). Simpler shapes in informal areas. }\end{array}$ & Settlement \\
\hline Dwelling road setback & $\begin{array}{l}\text { Distance of dwellings from roads. Precarious house placement and } \\
\text { lack of road setbacks expected in urban settlements. }\end{array}$ & Settlement \\
\hline Building density (dwelling separation) & $\begin{array}{c}\text { Spacing between buildings. A lower separation is expected in } \\
\text { informal settlements. }\end{array}$ & Settlement \\
\hline
\end{tabular}

Proximity to hazourdous or potentially hazardous areas, including e-flood zones, hydrologic setbacks, landslide/earthquake, garbage

Proximity to hazards mountains, point source pollution, airports, energy transmission lines, and major transportation. Informal settlements are more Environ likely to be closer to these hazards.

Properties (slope, elevation, aspect of the terrain, and soil type).

Geomorphology of terrain Settlements built in gullies, ravines, steep slopes, and unstable soils are more likely to be informal.

Proximity to city centre and social services

Temporal development
Driving distance to the city centre and other civic services, such as markets and healthcare facilities. Greater distances expected for informal settlements.

The temporal properties of the most recent land cover change. Informat settlements are expected to occur rapidly and present a large difference in cover type.
Environ

Environ

\section{Material and Methods}

\subsection{Area of Study}

The research was carried out in Jeddah, the most populous city in the west of Saudi Arabia, with an estimated 3.4 million residents in 2009 and an annual growth rate of 2.2\% (2010 census). Jeddah has a continually increasing number of urban settlements (Figure 1). The Jeddah Strategic Plan (2009) suggests that this driven by a shortage of housing for the growing number of low- and middle-income residents. Population growth within Jeddah is multifaceted, with new residents arising through natural growth, as well as illegal and 
legal immigration from outside the country and rural areas [47]. Currently, approximately a million people live in such conditions [48]. The geographic location of Jeddah is shown in Figure 2. For this study, a $70 \mathrm{~km}^{2}$ area was analysed; it is shown in Figure 2c. This area contains a mixture of vegetation and residential and commercial buildings, with the informal settlement section located mainly to the east.

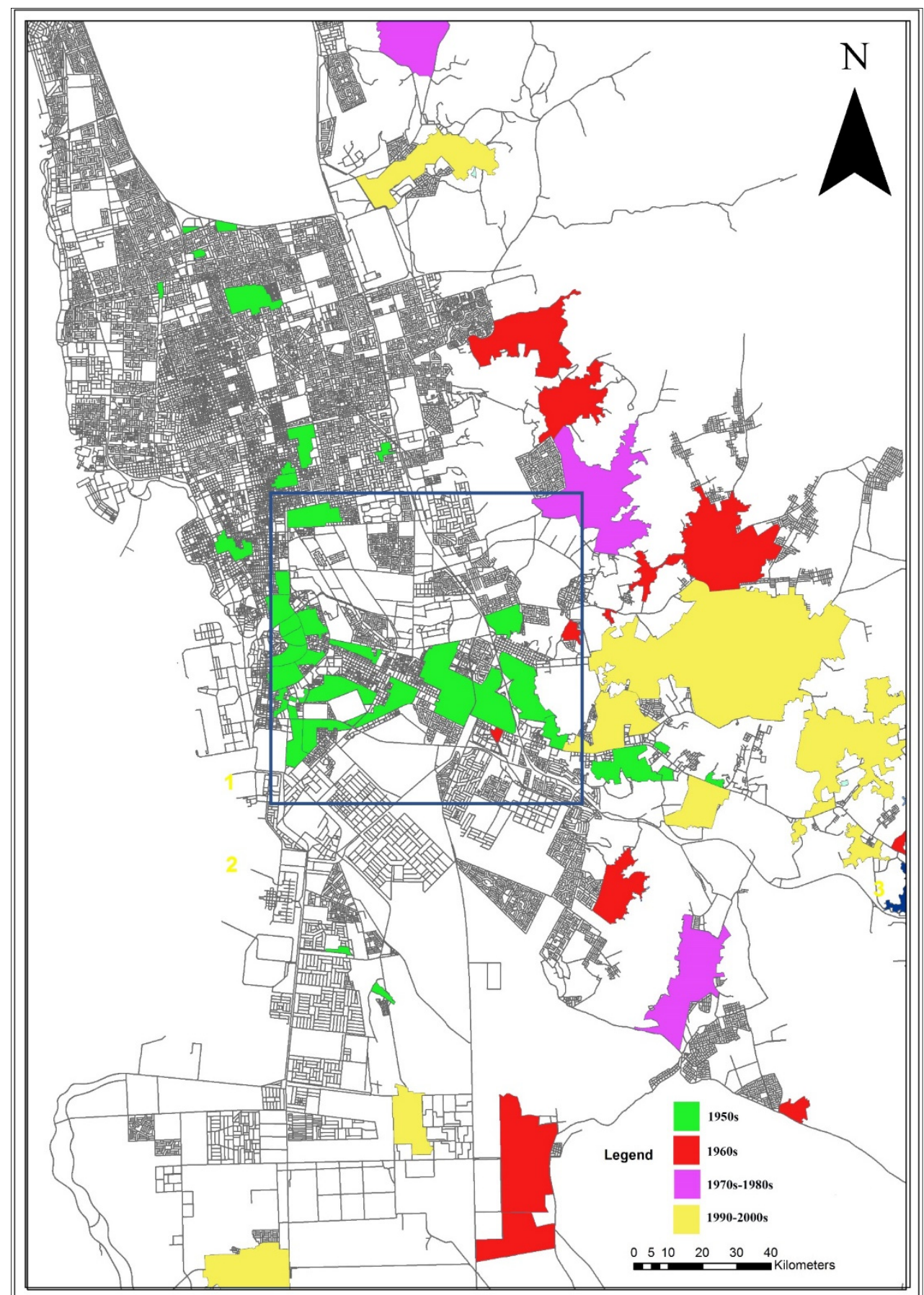

Figure 1. From the earliest informal settlement around the city centre (shown in green), via red and purple, to the most recently populated (yellow), the distribution of informal settlements based on Jeddah Municipality. 


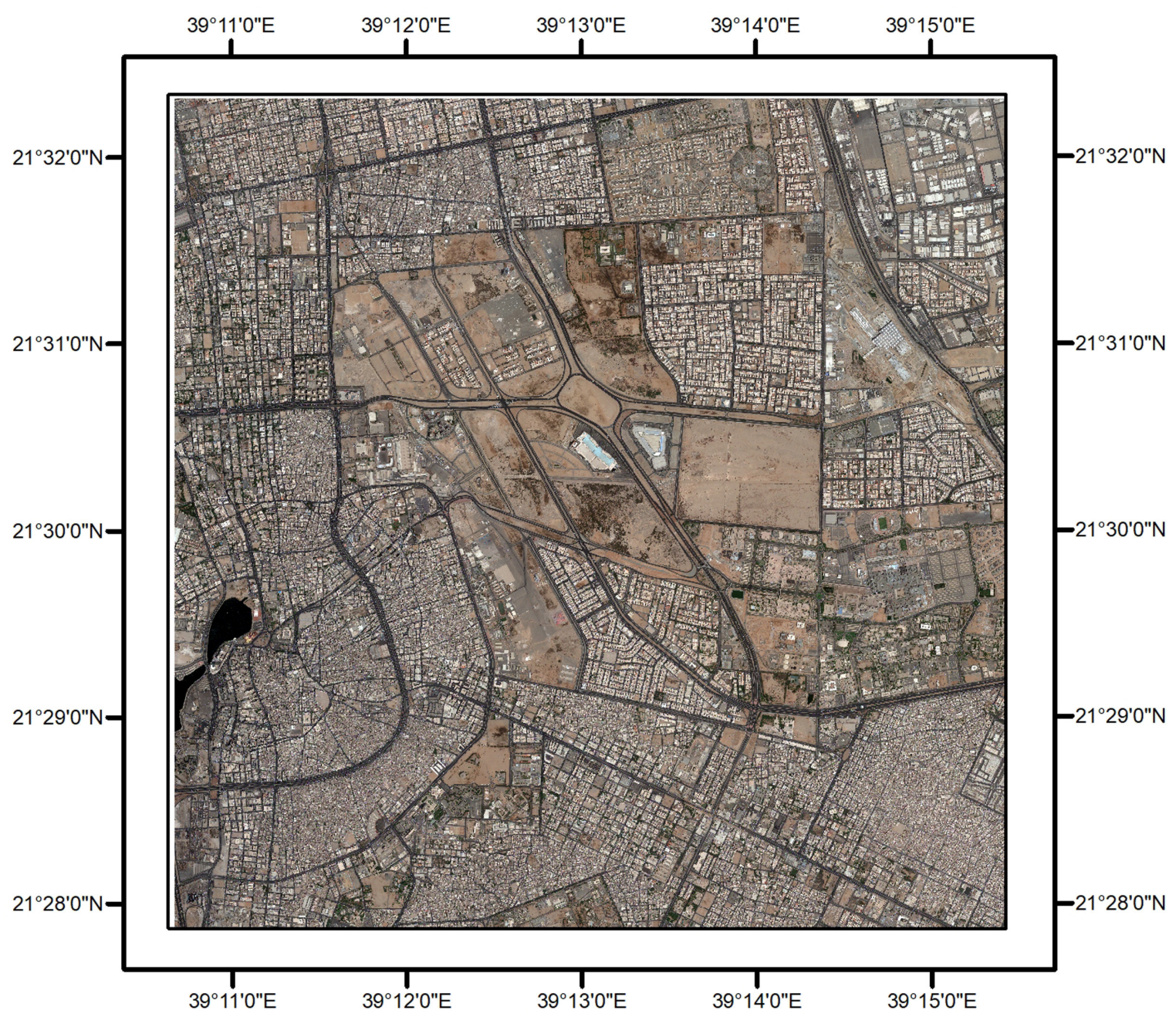

(a)

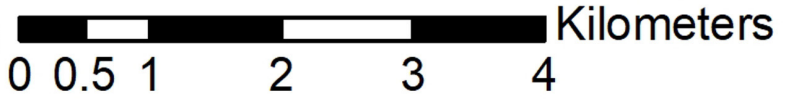

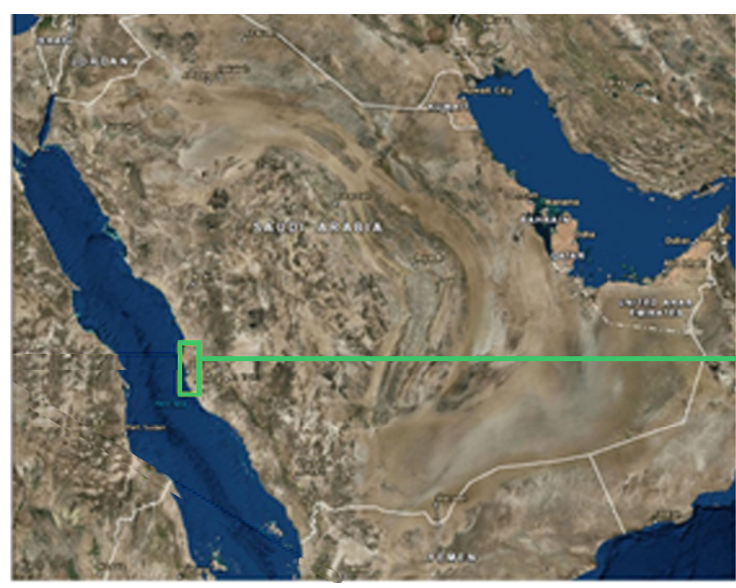

(b)

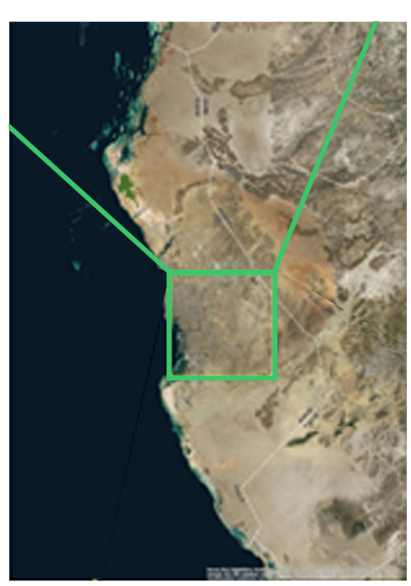

(c)

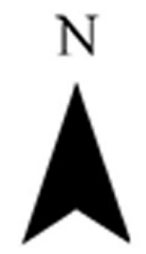

Figure 2. (a) The case study area investigated in this work; (b) Jeddah, a geographic region of Saudi Arabia (image courtesy of Google Earth); (c) the green rectangle displays the case study's extent.

\subsection{Dataset}

Two types of earth observation imagery were used in this study: single-date VHR imagery from the GeoEye-1 sensor, and medium-resolution imagery from the Landsat 
archive. The VHR image, which was used to map informal settlements in a previous study [28], was obtained on 8 January 2010, and has a resolution of $0.5 \mathrm{~m}$, panchromatic, and $2 \mathrm{~m}$, multi-spectral.

The medium-resolution imagery, which comprised an annual composite time series of 34 years covering the area archive, was created by combining many images using the method shown in [47]. The USGS archive provided all accessible Landsat TM and ETM+ data, as shown in Table 2, with less than 20\% cloud cover, from 1 June to 31 August (summer in the northern hemisphere) for the years 1984-2018 (path 170 and row 45). The Landsat ecosystem disturbance adaptive processing system (LEDAPS) algorithm was used to process surface reflectance information [48], which included a cloud mask computed with the Landsat cloud mask (FMask algorithm) [49]. Following [47,50,51], the annual summer composites were created using the best available pixel (BAP) method of image compositing. Figure 3 shows four annual composites of this time series, highlighting the dynamics of the urban extent of Jeddah from 1984 to 2018.

Table 2. Landsat TM/ETM + spectral bands.

\begin{tabular}{cc}
\hline TM Bands $(\mu \mathrm{m})$ & ETM + Bands $(\mu \mathbf{m})$ \\
\hline Band 1 $(0.45-0.52)$ & Band 1 $(0.45-0.515)$ \\
Band 2 $(0.52-0.60)$ & Band 2 $(0.525-0.605)$ \\
Band 3 $(0.63-0.69)$ & Band 3 $(0.63-0.69)$ \\
Band 4 $(0.76-0.90)$ & Band 4 $(0.75-0.90)$ \\
Band 5 $(1.55-1.75)$ & Band 5 $(1.55-1.75)$ \\
Band 6 $(10.40-12.50)$ & Band 6 (10.40-12.50) \\
Band 7 $(2.08-2.35)$ & Band 7 $(2.09-2.35)$ \\
\hline
\end{tabular}

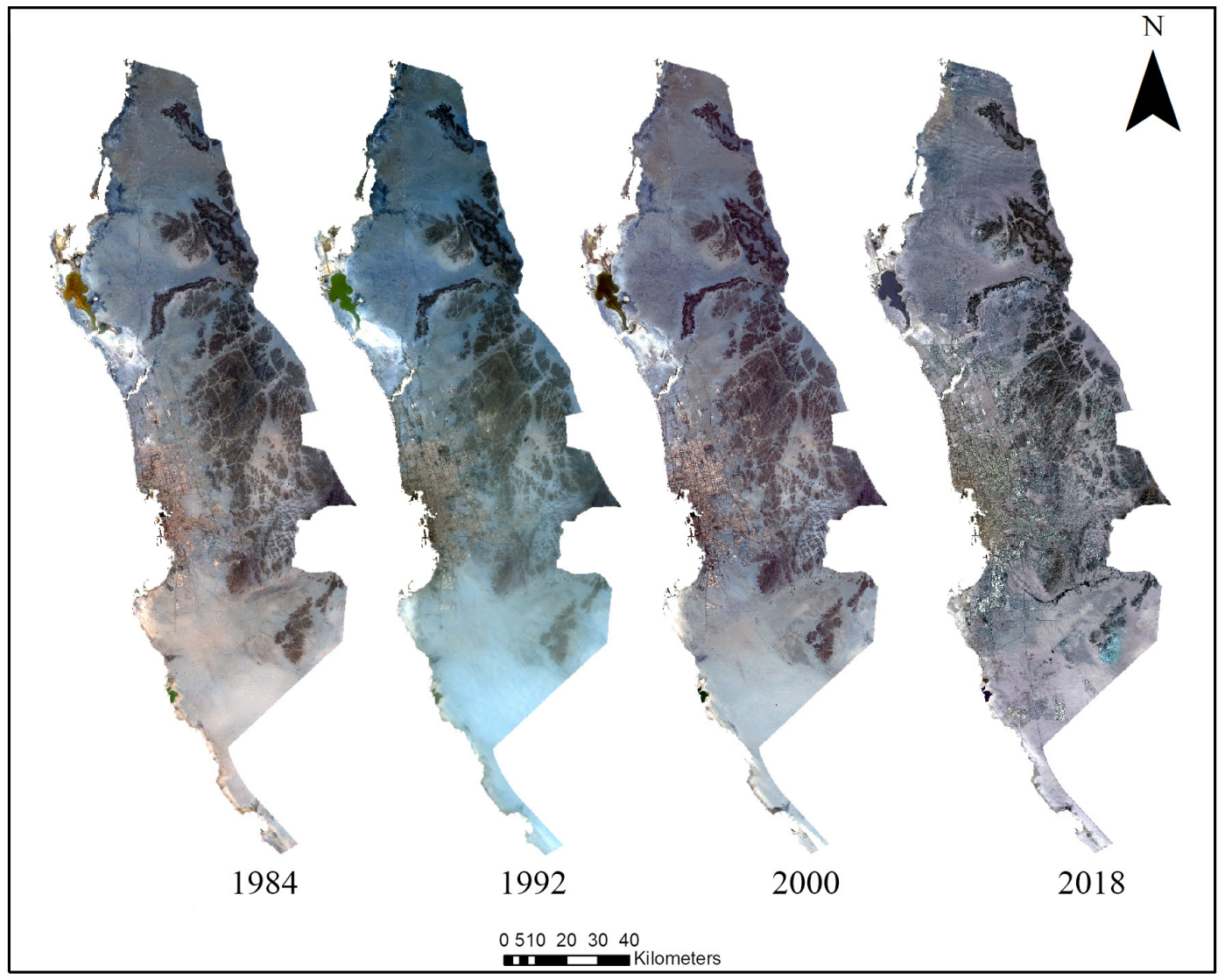

Figure 3. Landsat imagery for TM, ETM+, and OLI, presenting key development phases in Jeddah city through the time (1984-2018). 


\section{Methodology}

To combine object-based ML with time-series analysis, the ontological framework proposed was adopted from [45] and the informal settlement indicators suggested in [46] were used. This ontological framework consists of the object, settlement, and environment levels, as discussed in detail in [45]. The approach used to map remote-sensing-based features to this framework and these indicators within the context of Jeddah developed in [24] was adopted. In addition to the indicators and mapping proposed in [24], a temporal level and associated indicators were included and described using TSA.

Figure 4 depicts the workflow used to map and describe informal settlements through the combination of object-based ML and TSA. This process has three main phases: (1) TSA, (2) object-based image analysis, and (3) image classification, which are described in the following section. The method used to determine the success of the classification is also described. The findings of this research are presented at four spatial levels: object, settlement, environment, and temporal. In eCognition Developer 9.0, object-based mapping was implemented, as well as random forest in the R programming environment. In Appendix A, Table A1, there is a list of parameters and indices used to detect each indicator.

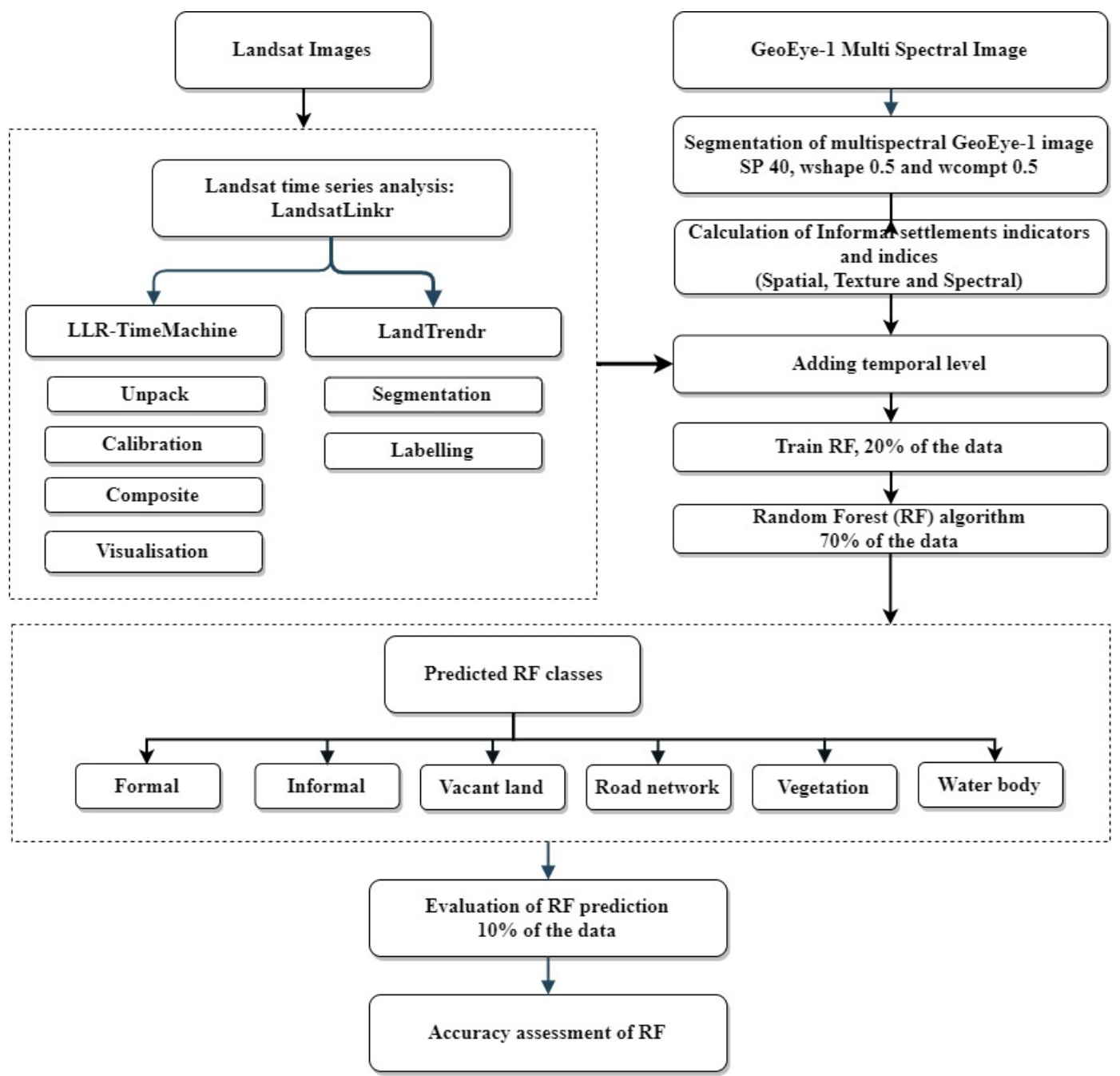

Figure 4. Flow chart for informal settlement identification in Jeddah using an object-based random forest approach that incorporates data from the LandsatLinkr.

\subsection{Time-Series Analysis (TSA)}

The TSA was completed in two steps using existing algorithms: LandsatLinker (LLR)TimeMachine and LandTrendr. LLR is a Landsat image-processing system that links images 
spatially and spectrally together over time, producing annual cloud-free image composites for spectral chronologies of 30 years or over [37,47]. The outputs are then used as inputs to map complex changes using LandTrendr.

\subsubsection{LandsatLinkr (LLR)-TimeMachine}

The LLR was explicitly developed and used extensively to assess changes in forested areas using annual Landsat time series [37,52]. LLR can be used to as an iterative method for segmenting each pixel's temporal trajectory into a sequence of straight lines (pointto-point and regression), allowing essential parameters, such as the year and the amount of the disturbance, to be detected. LLR is a tool to prepare Landsat images for further analysis. Landsat images from OLI, ETM+ and TM sensors were downloaded from [53]. These images were then used to create a temporal image composite.

This step shows the trend of each sample over the selected period (1984-2018). The main stages were the unpacking, the calibration of OLI to TM and ETM+, and the compositing of the images, as shown in Figure 4. Upon execution of the program, LLR was automatically run through all the procedures for a given step defined in the LLR workflow (Figure 4 below) for all the images in a given directory. For a detailed description of each procedure, see [47].

A cloud cover mask was measured by analysing clear-sky and cloud-contaminated data. For the reliable retrieval of LSTs, atmospheric profiles should be used as inputs for simulations of the up-welling and down-welling radiances and transmissivity based on a set of integration techniques [54]. By applying image cloud masks (including masking ETM+ poor scan lines) and combining numerous overlapping images from the same year into a single image using the mean [48] with version 0.5.0-beta, the time machine creates annual cloud-free composites in the final step of LLR.

\subsubsection{LandTrendr}

The segmentation and labelling processes were performed using ENVI software, in order to remove noise and simulate the main characteristics of the trajectory [47]. After eliminating the shallowest angle, a new segment was drawn between the two neighboring vertices, and all the vertex angles were recalculated. Change-labeling and spatial filtering were achieved by running an IDL batch file. Following [37], we used the default LandTrendr parameters, as shown in Appendix B Table A2. More detailed information about LandTrendr parameterisation and value ranges can be found in $[47,55]$. The LandTrendr labeling techniques were then used to extract the most significant disturbances for each pixel.

We calculated the four Landsat spectral indices of Tasseled Cap (TC), brightness (TCB), angle (TCA), wetness (TCW), and greenness (TCG), for each composite of surface reflectance $[35,47,56,57]$. TCA was used as it was found to be most sensitive for detecting changes in urban areas. Landsat imagery is frequently transformed using TC to minimize data volume and improve data interpretability by emphasizing the structures in the spectral data [56]. The trajectory for each index was then used to calculate the year and magnitude (spectral difference) of the greatest change of each pixel. The LandTrendr outputs were used as new indicators, as shown in Table 1, with the informal settlement indicators used in a previous study [28].

\subsection{Object-Based Image Analysis (OBIA)}

\subsubsection{Segmentation}

Object-based image analysis starts with image segmentation to generate coherent groups of similar pixels' details within the image $[58,59]$. For this study, the aim of this process was to represent basic land cover objects (buildings, road segments, grass patches) as individual segments. Segments were generated from the VHR using the multi-resolution segmentation tool in eCoginition following [23-25,60]. The parameterisation consisted of a scale parameter of 40 and weights of 0.5 for both shape and compactness. 


\subsubsection{Object Attribution}

Following the segmentation, individual objects were attributed with image and TSA features that acted as informal settlement indicators. These features can be divided into three categories: spectral, shape, and temporal. The spectral features for each object were derived from the VHR and consisted of the built-up area index (BAI) [28] and the normalized difference vegetation index (NDVI) [61] and texture measures (contrast, entropy, homogenous, correlation, and mean) calculated using the grey-level co-occurrence matrix (GLCM) approach $[1,62,63]$.

The temporal features derived from the TSA (year and magnitude of last change) were also calculated for each segment. As the segmentation and Landsat time series were not coaligned, the temporal features were assigned using zonal statistics, where the segment was attributed with the value from the TSA covering the largest proportion of the segment area.

\subsection{Random Forest Classification}

The random forest classification algorithm was used to classify objects into the six land cover classes; informal settlements, formal settlements, vacant land, vegetation extent, road networks, and water bodies. In order to determine the effect of including TSA features, the classifier was run twice, once with the TSA features, and once without. McNemar's test was then used to compare the classifications. The null hypothesis of McNemar's test states that the same proportion of the population will be accurately identified with and without TSA measurements [64].

\section{Training Data}

A visual interpretation of the VHR imagery was used to acquire the reference data. A stratified random distribution was used to choose the training data to represent each class, such as a road network and a built-up area. An overall number of 4,500 samples was chosen from the colour composite image, illustrating the variety of the image component sizes and shapes. This approach was used to ensure a statistically robust sample that was representative of the entire study area. At each point, the interpreter used the information within an image, as well as local knowledge, to allocate the point to one of the six classes (formal settlement, informal settlement, bare ground, vegetation, roads, and vacant land).

\subsection{Accuracy Assessment}

To assess the classification accuracy, an out-of-the-bag (OOB) sample statistic was used. These estimates were performed OOB (see Figure 4), as explained in [65]. Random forest multiple decision trees were trained on a bootstrap sampling of the original training data. As is common practice (e.g., [66,67], to acquire the best result, we ran the re-sampling process 500 times. One randomly selected group of input parameters was picked as the optimal split and used for node splitting at each node of every decision tree [68]. For interpretation and prediction, variable selection is critical, especially for multi-dimensional datasets. In this paper, the importance of the variables was ranked using a relative importance graph.

\section{Results}

The findings of the mapping of the informal settlement indicators, including the results of the LLR time machine technique, are presented in this section.

\subsection{Time Series Analysis}

After evaluating all the temporal trajectories, we found the temporal TCA median trajectory to be a good candidate to represent the changes over the 34 years from 1984 to 2018. Figure 5 shows the outputs (year, duration, and magnitude of greatest change) of the LandTrendr for the Jeddah area. These outputs demonstrate the dynamic nature of areas of known informal settlements. For example, it is clear that significant changes occurred in 
the region in the period between 1990 and 2002 (see Figure 5). Such changes can be linked to development stages at the city scale [4].

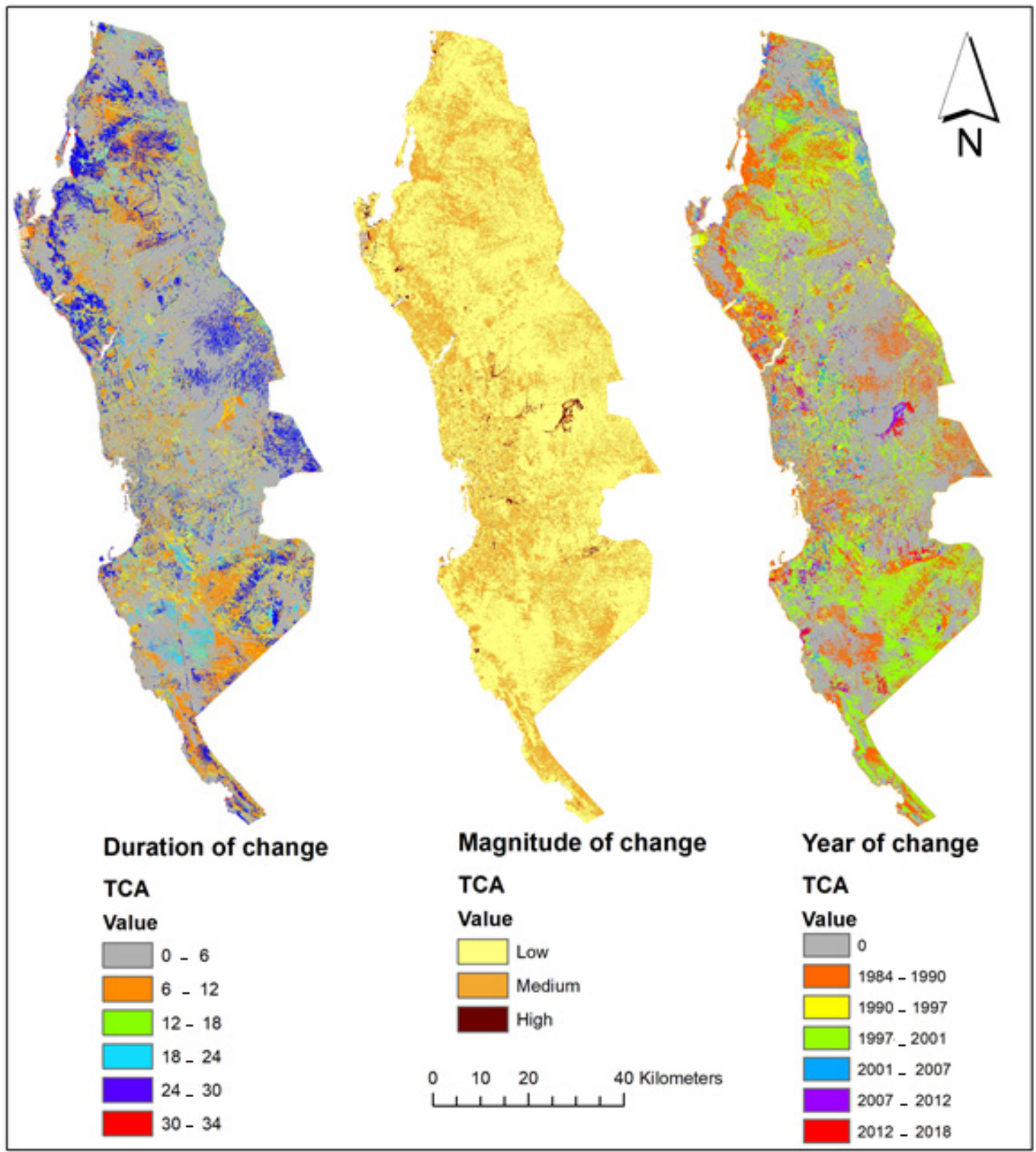

Figure 5. Example of TCA results in the case study. The image on the left represents the duration of the change within the 34 years. The image in the middle represents the magnitude of the change. The image on the right represents the year of the change.

\subsection{Classification Accuracy}

The overall accuracy of the classification using the outlined approach was $94 \%$ and $95 \%$ with and without the inclusion of the TSA variables, respectively (see Figure 6). Based on McNemar's research, the inclusion of TSA variables was not found to provide a significant increase in the classification of all the classes $(p=0.03)$. In general, the results were highly encouraging, with user and producer accuracies over $90 \%$ in all the classes. At the individual class level, small improvements were seen in the producer's accuracy. Table 3 documents the usefulness of using TSA as an additional dimension to enhance the mapping of informal settlements. As a slight increase in accuracy was observed with the 
inclusion of TSA descriptors, the remainder of this section focuses on the classification with TSA descriptors included. For example, there was a noted improvement in all the classes except for vacant land. There was a slight improvement in the detecting width of the road network and an increase in the road network connectivity. The improvement in the road networks resulted from a clear distinction between built-up areas and other classes, such as vacant land, as shown in Figure 7. Figure 8 shows the relative importance of the 30 variables used within the classification. In general, the indicators played a large role in identifying informal settlements, while they had less impact on the TSA variables. Of the two TSA variables included, the year of change had a higher relative importance than the duration of change, which ranked last out of all the included variables.

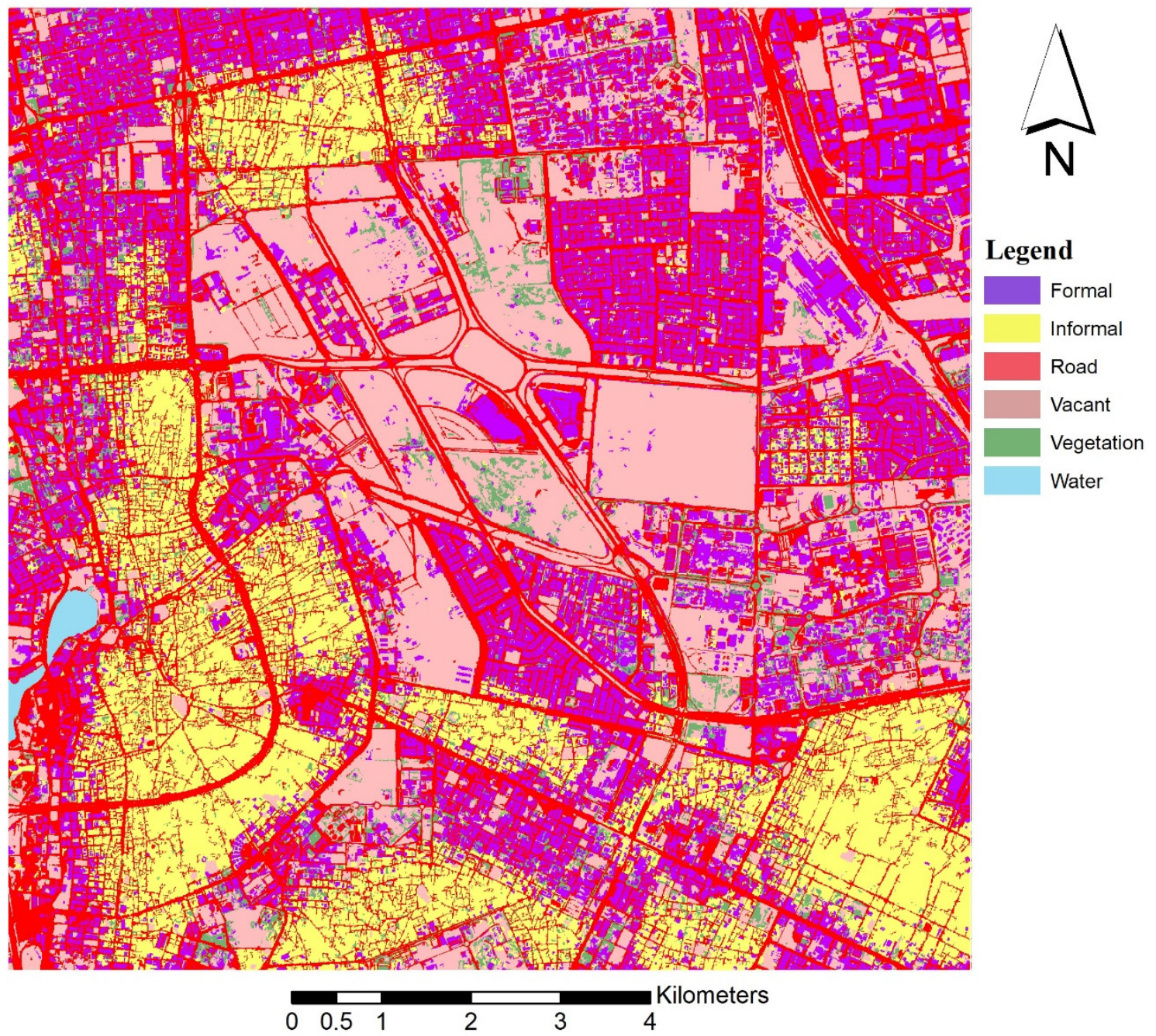

Figure 6. The results of the predicted classes using object-based ML with TSA classification.

Table 3. Summary of the accuracy assessment results obtained with and without TSA using objectbased ML and TSA.

\begin{tabular}{cccc}
\hline \multirow{2}{*}{ Compared Results } & \multicolumn{2}{c}{ Mapping Accuracies } & Difference/Improvement \\
\cline { 2 - 3 } & without TSA & with TSA & $2 \%$ \\
\hline Formal & $92 \%$ & $94 \%$ & $2 \%$ \\
Informal & $95 \%$ & $97 \%$ & $1 \%$ \\
Road network & $89 \%$ & $90 \%$ & $-1 \%$ \\
Vacant land & $94 \%$ & $93 \%$ & $1 \%$ \\
Vegetation & $95 \%$ & $96 \%$ & No change \\
Water body & $100 \%$ & $100 \%$ & \\
\hline
\end{tabular}




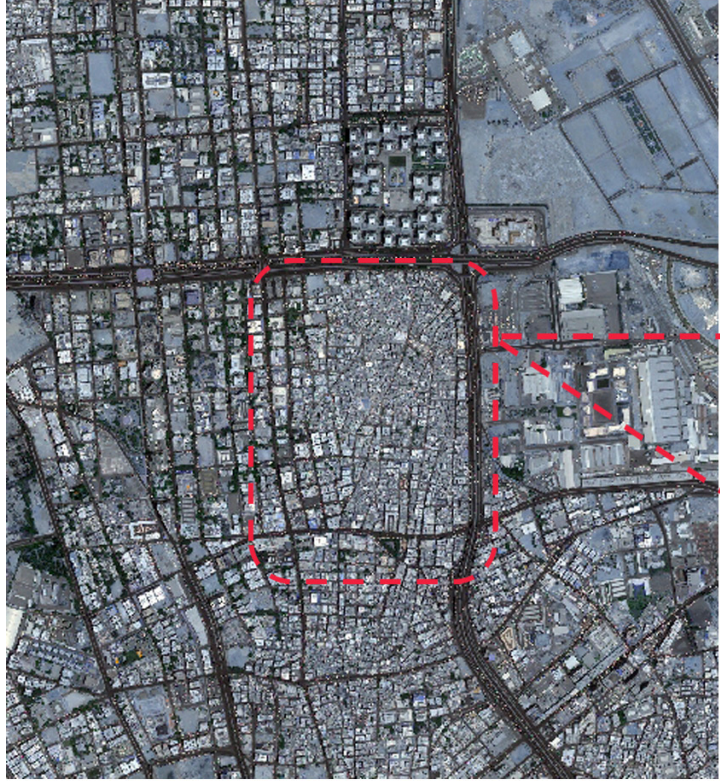

(a)

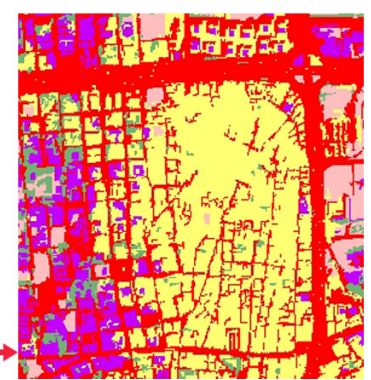

(b)

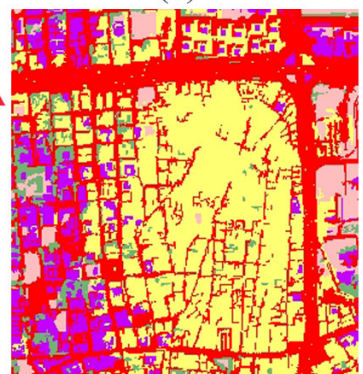

(c)

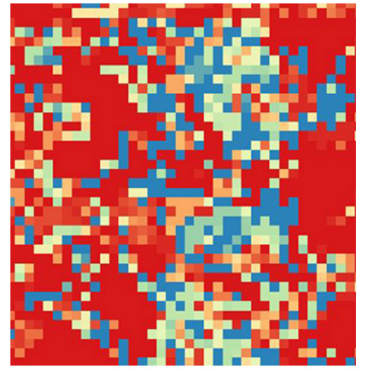

(d)

No Change

5

10

15

20

25

30

34

Figure 7. The main difference between formal and informal road networks. (a) A GeoEye-1 image (b) shows mapping results without TSA, while (c) shows the mapping results using TSA. The result shows an improvement in the connectivity of road network and enhancing road widths. (d) The year-of-change results inside an informal settlement.

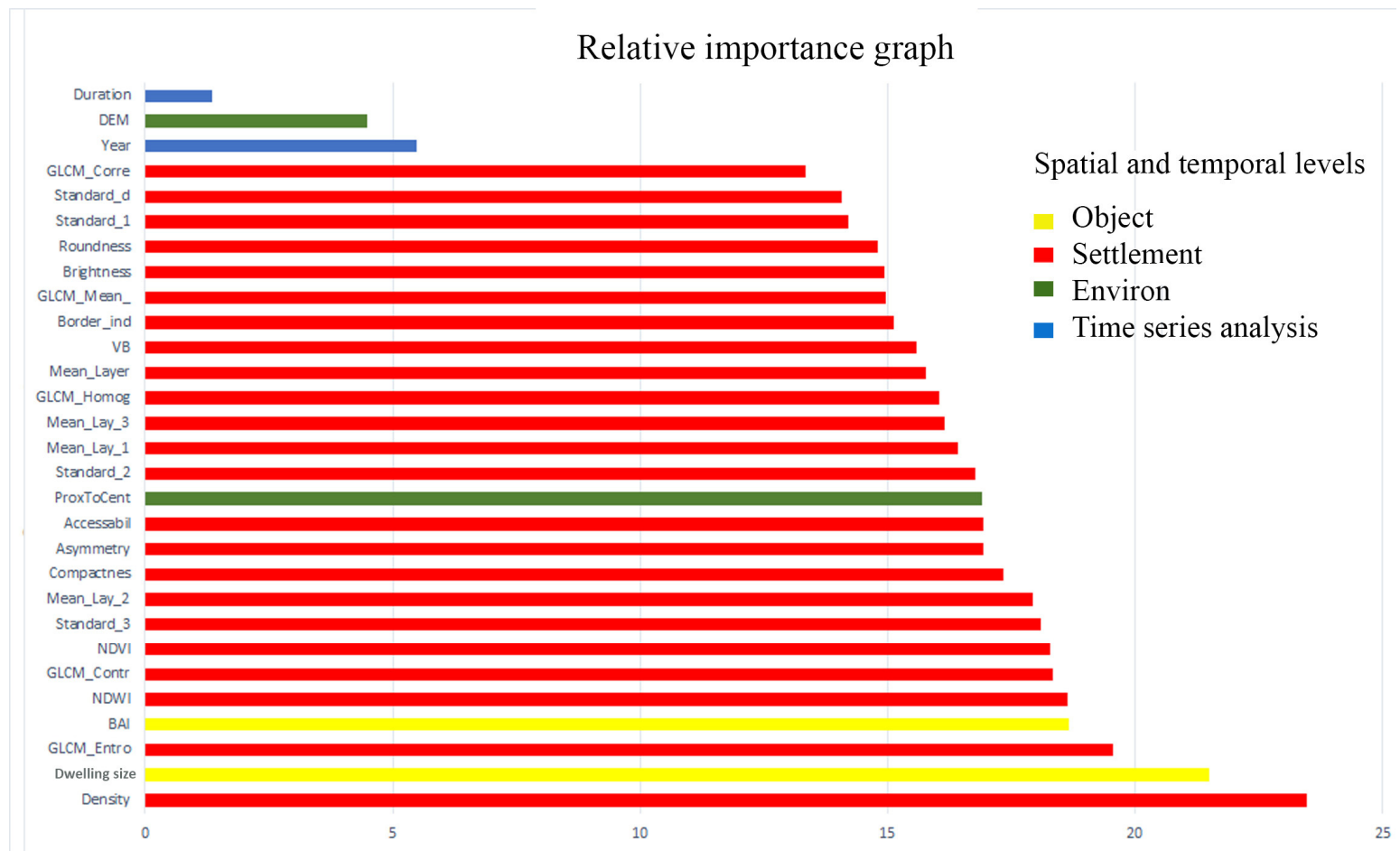

Figure 8. The relative importance of 30 object-based random forests with TSA classification variables in four different spatial and temporal levels. Red bars represent the settlement level, yellow the object level, green the environ level, and blue the time-series analysis.

At the object level, dwelling size was ranked second in importance, with a relative importance of 23, followed by roofing; built-up areas, using the built-up area index (BAI), 
were fourth (see Figure 8). The dwelling size contributed to the classification with a relative importance of 23 and ranked fourth in relative importance.

At the settlement level, density was the most crucial variable, with a relative importance of almost 24. The most essential sources of information for distinguishing informal settlements from other classifications were the density and texture measurements. Generally, among all the spatial and spectral variables, the settlement variables contributed the most. Of the five texture measures, the GLCM entropy $_{\text {and }}$ GLCM $_{\text {contrast }}$ were the most successful parameters, rated fifth and sixth in the importance graph, with a relative im-

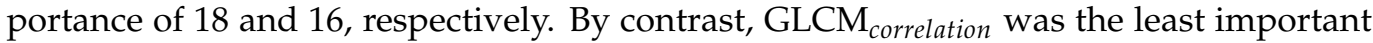
variable at the settlement level, with a relative importance of 14 . The high sensitivity of the green band to urban areas rated the green band as seventh in importance, with a relative importance of 18, sharing the same contribution to the model as the texture measures. The NDVI index was used mainly due to its sensitivity to vegetation. The NDVI index was rated among the top variables, which allows the detection of the vegetation extent indicator with $96 \%$ accuracy.

The analysis was performed twice with and without TSA to evaluate the utility of TSA using the random forest model. Therefore, the contribution was checked based on the classification performance of each class and its overall accuracy. The impact of the vegetation extent was significant due to the sensitivity of seasonal change. The formal class was completed with a $4 \%$ increase in producer accuracy. The road network came in second, with a producer accuracy of 3\%. However, there was a slight drop in accuracy (2\%) when mapping informal settlements and vacant land almost. Figure 9 shows the annual composite of formal and informal trend patterns. The similarity of the spectral characteristics reduced the benefit of TSA. Therefore, utilising TSA for enhancing informal settlement identification requires clear and distinct spectral characteristics [4]; an urban development should be within the scope of the used images to represent this development. Despite this constraint, high-resolution spectral and temporal resolutions were proven to be critical for exploring new ways to investigate urban landscapes utilizing VHRe metrics [69].

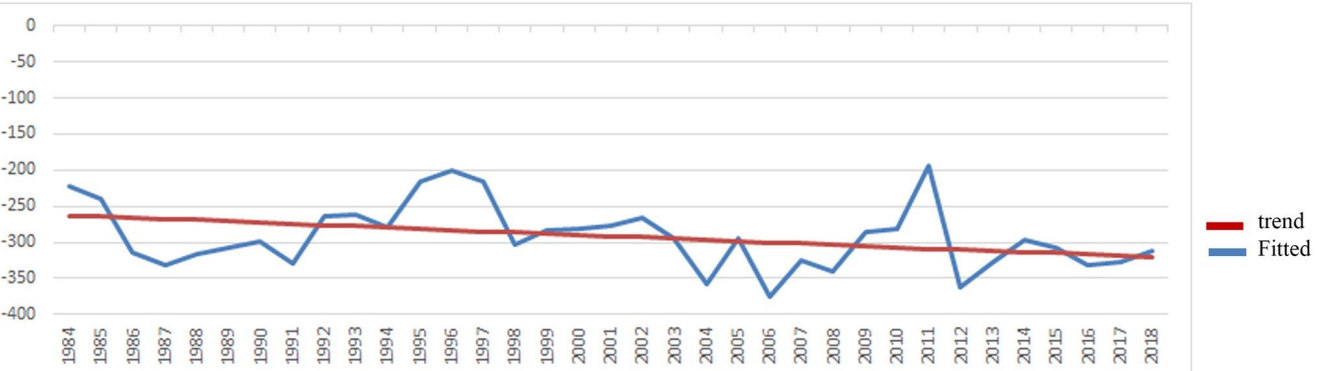

(a)

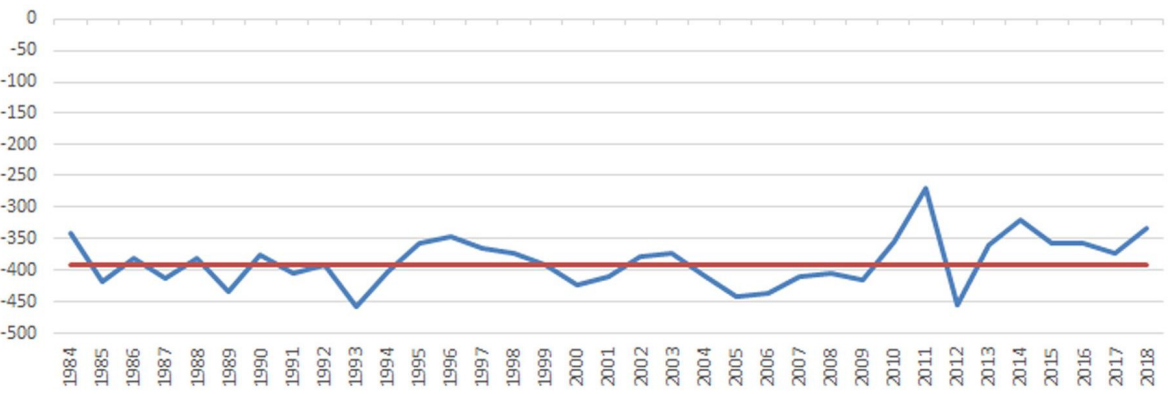

(b)

Figure 9. Annual composite of chosen class from 1984 to 2018. (a) A TCA trajectory of the formal area. (b) A TCA trajectory of an informal settlement representing changes.

Roofed and built-up areas, as measured by the built-up area index (BAI), were ranked third in importance at the object level, with a relative importance of $20 \%$, followed by 
dwelling size, as shown in Figure 6. With a relative importance of 18.1 and ranking fourth in relative importance, the housing size contributed to the classification.

At the settlement level, density was the most crucial variable, with a relative importance of almost 24. Density and texture measures were the most important sources of information for distinguishing informal settlements from the other classes. Generally, among all the spatial and non-spatial variables, the settlement variables contributed the most. The most successful texture measures were $\mathrm{GLCM}_{\text {contr }}$ and $\mathrm{GLCM}_{\text {entro }}$, which were ranked fifth and sixth on the importance graph, respectively, with a relative importance of $18 \%$. At the settlement level, however, GLCM corre $_{\text {was }}$ the least important variable, with a relative importance of $14 \%$. Because of the green band's strong sensitivity to urban areas, it was ranked seventh in importance, with a relative importance of 18 , and it made the same contribution to the model as the texture measurements. The NDVI index was used mainly due to its sensitivity to vegetation. The NDVI index was rated among the top variables which allows the detection of the vegetation extent indicator with $96 \%$ accuracy.

The geomorphology of the terrain indicator (DEM) had the least impact on the classification at the neighborhood level, with a relative importance of $4 \%$. Proximity to the city centre had the greatest impact on the environment, accounting for $17 \%$ of the total.

At the temporal level, the results showed the slight importance of the environment level, i.e., DEM, with a $6 \%$ relative importance; the year of change was found to be the most significant indicator contributing to the random forest model. One the other hand, the magnitude of change had the least impact on the classification using the random forest model. The year of change, the magnitude of change, and the informal settlement boundary contributed to the overall accuracy and to the accuracy of each class classification (see Figure 10).
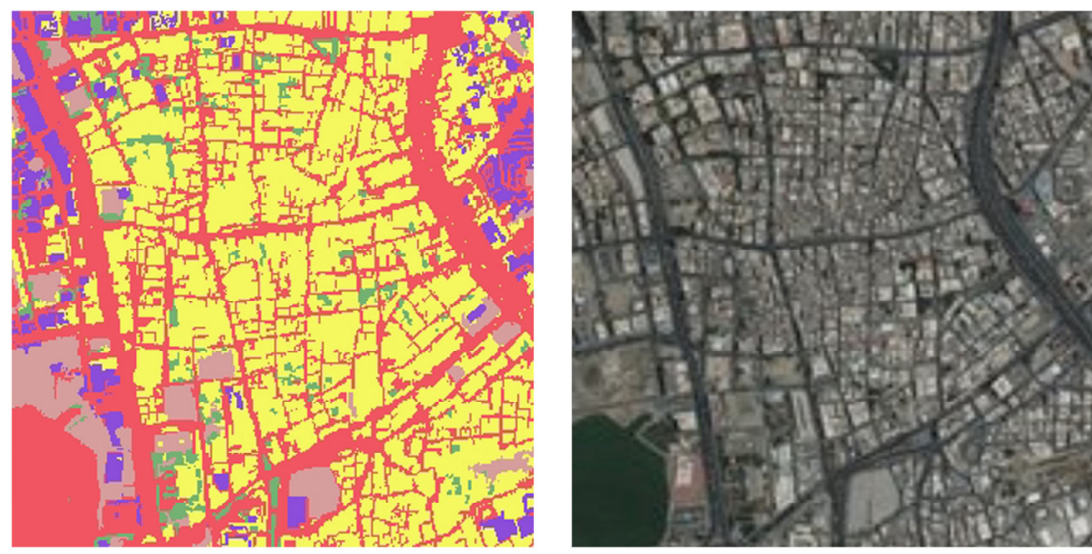

Figure 10. The performance of object-based ML and TSA mapping in an informal settlement. The results were not limited to the informal boundary because they depend on many indicators, such as texture measurements, size, and density.

\subsection{Temporal Analysis of Informal Settlements}

While the use of the TSA approach led to a significant improvement in the classification accuracy of informal settlements, we also used the information from this approach to gain a greater understanding of the evolution of the area and its informal settlements. For example, $62 \%$ of the study area was found to have undergone a change (or disturbance) in its spectral characteristics. The greatest amount of change was seen in areas classified as roads using the object-based approach $\left(7.2 \mathrm{~km}^{2}\right)$. Furthermore, $52.1 \%$ (or $6.0 \mathrm{~km}^{2}$ ) of the area classified as informal settlements was found to have been disturbed since the beginning of the time series (1985). Areas with spectral disturbance early in the analysis period were found to mostly occur within or around existing settlements. The majority of areas were shown to have changed later in the study period, occurring in small clusters or in isolation from the larger urban settlements. 


\section{Discussion}

This study applied a ML approach for mapping informal settlements using the VHR, OBIA-ML, and TSA analysis paradigm. As a hierarchical procedure, the OBIA approach has been the most popular strategy used to solve complex pattern classifications over the past decade $[70,71]$. Currently, ML algorithms have become good candidates to overcome some of OBIA's problems, such as its ingestion of big data sets and poor accuracy [4]. The utility of OBIA in identifying informal settlements with ML was evaluated in [28]. Here, a new data set, based on a time-series analysis of medium-resolution imagery, was evaluated for informal settlement mapping.

With the inclusion of the time dimension, a slight improvement in accuracy was achieved, as shown in the relative importance graph in Figure 6. However, the overall accuracy of the random forest classification was high (95\%) compared with [28] The structure of the urban characteristics, in general, is complex to present because of the large variation in the urban context in VHR satellite imagery [15,72]. Mapping urban dynamics at fine spatiotemporal resolutions is critical for sustainable urban development [73]. The use of time-series analysis with LandTrendr as input data in a ML classifier made the least contribution to the model. However, it helped to achieve better accuracy for each predicted class (see Table 2), which resulted in better overall accuracy. LandTrender is a pixel-based algorithm and a generalisation of the results should be performed to combine it with segments generated from VHR imagery. Furthermore, the method is very sensitive to natural changes because it is mainly designed for forest mapping. However, the method gives a wider view of city-scale development phases using free data sources. Currently, the identification of the temporal dynamics of urban development phases over three decades is available to informal settlement authorities and governments in developing countries. Based on the municipality of Jeddah's strategic plane, this case study is part of the beginning of urban expansion from the old city centre more than 30 years ago through to recent developments. This can explain the lower impact of time dimensions on the classification contribution when less development accrued, as shown in Figure 1.

Figure 11 shows the timing of the changes that occurred inside the informal settlements within the study area. This figure shows that TSA is very useful for understanding the evolution and growth direction of informal settlements. While these changes do not necessarily inform the year in which the informal settlements were formed, they do provide an indication of changes within the settlement. Therefore, TSA is a powerful tool for local authorities, such as urban planners and governors, to monitor changes, as well as determining their dimension and direction. This can help to control illegal growth and allow reporting to SDGs.

The strengths of the inclusion of TSA within the developed method for informal settlement mapping are as follows. First, the Landsat satellite data and the associated TSA algorithms are currently freely available. Since the required LandSat long archive data is freely available, this can help local authorities to monitor and manage the spatial distributions of informal settlements in countries in the global south, where there are budget shortages. Second, the approach allows a quick overview on city or country scales. Third, the modelled results give a quick overview of where to proceed with deeper, more detailed analysis. However, the most significant disadvantage of an approach using this data is the level of detail of descriptors appearing on the images and in the reference data set on the ground. However, to maximize the facilitation of mapping informal settlements using the Landsat data, development phases at the city scale should be considered. Current mapping paradigms and data combination need further investigation. 


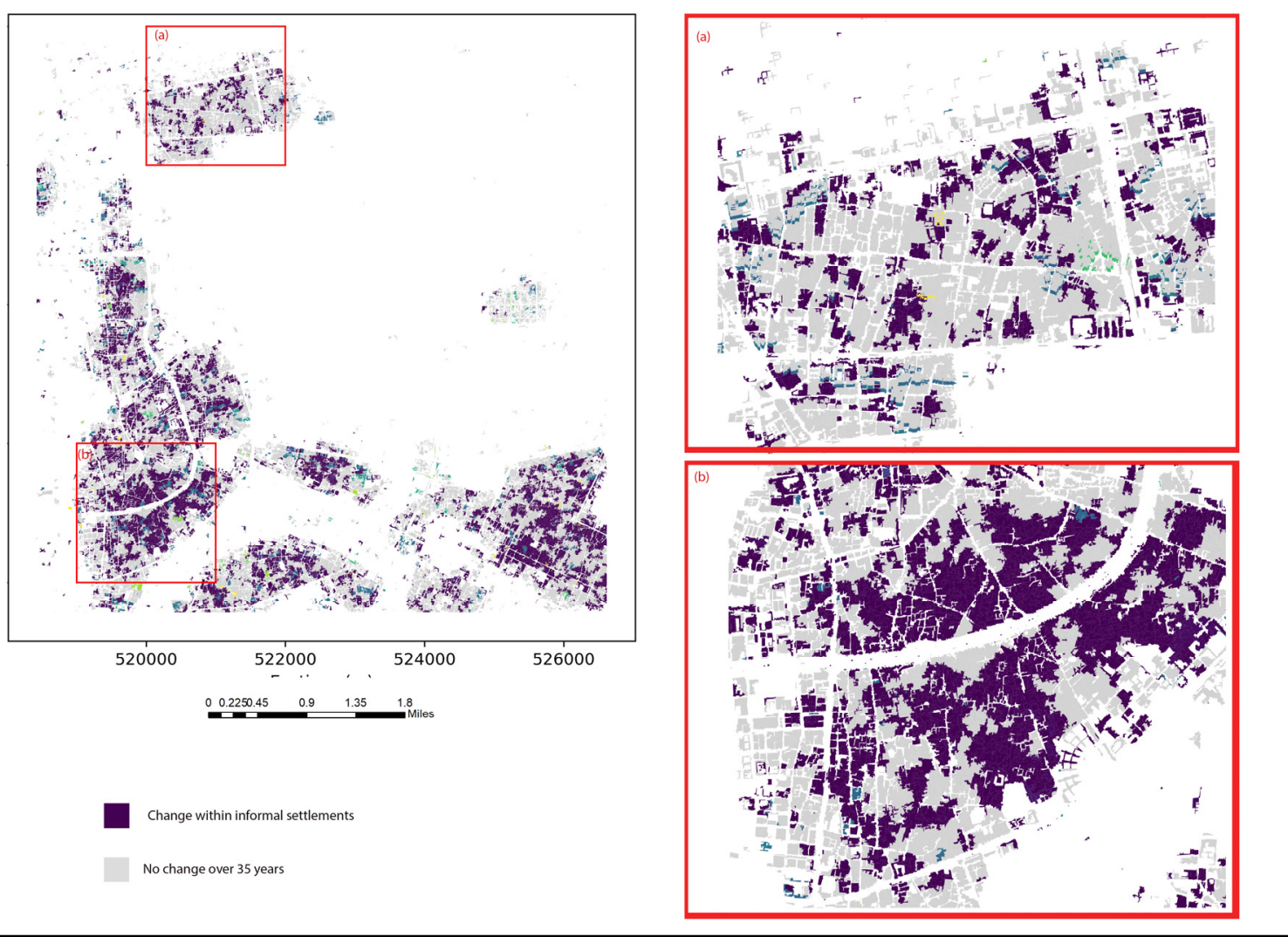

Figure 11. The year of change, as indicated by the Landsat time series analysis, within areas classified as informal settlements using object-based random forest classification. The grey indicates areas classified as informal settlements that showed no land use or land cover changes after the beginning of the time-series analysis period.

At the object level, both dwelling size and roofing and built-up areas were significant based on their contribution to the model classification, with a relative importance $>20 \%$, as shown in Figure 6. Buildings in the Middle East are vary widely in terms of size, colour, shape, tone, and texture, according to visual interpretations of urban fabric. As can be seen in Figure 12, dwellings of the same size were mapped as informal settlements even though they were outside the district extent, as well as being surrounded by the main road network.

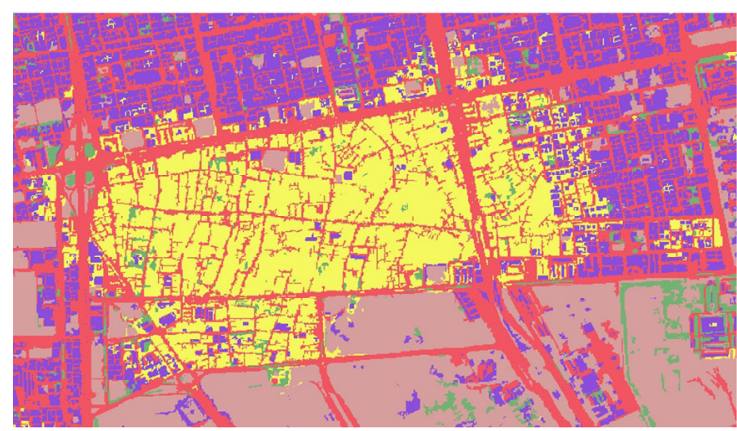

(a)

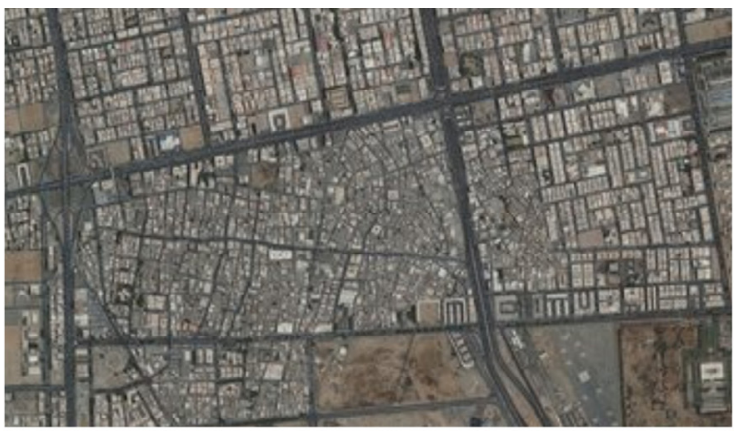

(b)

Figure 12. The impact of dwelling size and other indicators on informal settlement mapping. (a) Shows the informal settlement (Bin Malek district) in yellow, (b) shows the used GeoEy1-1 satellite imagery in random forest classification. 
At the settlement level, in developing countries, the road networks within informal settlements and rural areas are often unpaved and irregularly patterned [74]. Therefore, urban road networks are challenging to map. To solve this issue, the normalized difference water index (NDWI) was used to enhance the connectivity of the mapping of the road networks $[25,74,75]$. Although there were differences in road networks between formal and informal areas, such as elongation and regularity, road networks were identified with a producer accuracy off $90 \%$ and a user accuracy of $93 \%$.

Informal settlements have become dominant descriptors in urban areas. Structural and textural variables are significant when identifying such descriptors [76]. Texture measures were used frequently to map informal settlements in a different context $[1,23,25,76]$. Five texture measures using the grey-level co-occurrence matrix (GLCM) were calculated to detect a vector that describes the texture of each segment based on Haralick's method [63]. Among all the GLCM variables, GLCM $M_{\text {Contr }}$ and GLCM Entro rated third and fourth, respectively, in the relative importance graph. Roofing texture in an informal settlement is homogeneous and has high entropy [24], which makes it possible to differentiate between formal areas and informal settlements. This finding demonstrates the effectiveness of texture measurements, such as image segment variation or repetition evaluated by spectral intensity, for determining differences in informal settlements [46]. The importance graph in Figure 10 shows that the texture measurements varied due to the textural homogeneity inside the informal settlements. With a relative relevance of $14 \%$, the GLCM $M_{\text {correlation }}$ variable had the lowest impact on classification at the settlement level. Adding texture measures to ML approaches enhances the value of categorisation results when employing VHR imagery, especially in metropolitan settings $[77,78]$.

The performance of the indicators at the environment level was less relevant and scored lower than the indicators at the settlement and object levels, with a relative relevance ranging from $4 \%$ to $12 \%$. The distribution of informal settlements occurs frequently outside of city centres $[24,46]$. This was not always the case, however. As a result, the proximity indicator showed a lack of descriptive capabilities. Moreover, DEM had the least effect on the classification at the environ level, with a relative importance of less than $5 \%$. Since the terrain was almost flat, the formal and informal settlements were found to be equally subject to flood hazards. When informal areas are located along river banks or on steep slopes, the terrain can be highly useful for detecting them [23]. Figure 11 shows the temporal characteristics of the areas classified as informal settlements within the study area. The purple shows the changes in dwellings occurring inside informal settlements. The grey represents the areas that experienced no changes over 35 years.

\section{Conclusions}

The proposed method was structured to be transferable to the mapping of informal settlements in comparable metropolitan settings. Unlike OBIA, the object-based ML and TSA technique using VHR and Landsat remote sensing images does not necessitate parameter optimisation. The proposed methodological framework combines the benefits of using OBIA and ML to tackle variability in VHR imagery and complex urban patterns. The overall goal of this research was to design a reliable classification approach for informal settlement mapping utilising OBIA-ML and TSA based on Landsat and VHR images. The random forest approach showed the importance of each data input at all levels. Therefore, the utility of each indicator can be evaluated for informal settlement identification by local authorities based on the local context. The overall accuracy of the informal settlement mapping using the proposed paradigm was $95 \%$. According to this study, the indicators at the settlement level had the highest impact on the informal settlement mapping. The study concludes that adding the temporal level enhanced the mapping and monitoring of the spatial distribution of informal settlements at the city scale rather than the neighbourhood scale.

Author Contributions: A.F., S.J. and D.M. conceived and designed the experiments; A.F. and L.W. performed the experiments; A.F. and L.W. analysed the data; and A.F., S.J., L.W.; and D.M wrote the paper. All authors have read and agreed to the published version of the manuscript. 
Funding: This research received no external funding.

Data Availability Statement: Not applicable.

Acknowledgments: Fallatah thanks the Digital Globe Foundation for providing GeoEye-1 images for this research, and the support of the Municipality of Jeddah is acknowledged.

Conflicts of Interest: The authors declare no conflict of interest.

\section{Appendix A}

Table A1. Informal settlement indicators and parameters used for object-based ML classification in the Middle East environment. The first six indicators appended with $\left({ }^{*}\right)$ were used only in the [25], using the OBIA approach. In this work, all the informal settlement indicators were adopted.

\begin{tabular}{|c|c|c|c|}
\hline $\begin{array}{c}\text { Informal } \\
\text { Settlements/Variable }\end{array}$ & Parameters & Description & Equation/Tool \\
\hline * Built up area & Built up area index (BAI) & $\begin{array}{l}\text { BAI is used to measure } \\
\text { Built-up area. }\end{array}$ & $\mathrm{BAI}=(\mathrm{B} 1-\mathrm{B} 4) /(\mathrm{B} 1+\mathrm{B} 4)$ \\
\hline * Dwelling size & Area & $\begin{array}{l}\text { The number of pixels forming } \\
\text { an image object. Mean } \\
\text { dwelling sizes between }<50 \\
\mathrm{~m}^{2} \text { and } 380 \mathrm{~m}^{2} \text { classified as } \\
\text { informal settlements. }\end{array}$ & Object feature in eCognition \\
\hline * vegetation & $\begin{array}{l}\text { Normalised Difference } \\
\text { Vegetation Index (NDVI) }\end{array}$ & $\begin{array}{l}\text { NDVI is used to measure } \\
\text { vegetation. }\end{array}$ & $\mathrm{NDVI}=(\mathrm{B} 4-\mathrm{B} 3) /(\mathrm{B} 4+\mathrm{B} 3)$ \\
\hline $\begin{array}{l}* \text { Lacunarity of housing } \\
\text { structures }\end{array}$ & Visible brightness (VB) & $\begin{array}{c}\text { The mean intensity of all the } \\
\text { image bands for an image } \\
\text { object. }\end{array}$ & $\mathrm{VB}=(\mathrm{B} 1+\mathrm{B} 2+\mathrm{B} 3) / 3$ \\
\hline $\begin{array}{c}* \text { Road segment type and } \\
\text { materials }\end{array}$ & $\begin{array}{l}\text { Normalised difference water } \\
\text { index (NDWI) }\end{array}$ & $\begin{array}{l}\text { NDWI: An index developed } \\
\text { to distinguish tarred roads } \\
\text { from other classes. }\end{array}$ & $\mathrm{NDWI}=(\mathrm{B} 2-\mathrm{B} 4) /(\mathrm{B} 2+\mathrm{B} 4)$ \\
\hline * Texture measures & $\begin{array}{l}\text { Grey-level co-occurrence } \\
\text { matrix (GLCM) }\end{array}$ & $\begin{array}{l}\text { GLCM entropy } \\
\text { GLCM homogeneity } \\
\text { GLCM contrast } \\
\text { GLCM correlation } \\
\text { GLCM mean. }\end{array}$ & Object feature in eCognition \\
\hline Road accessibility & Accessibility & $\begin{array}{l}\text { Based on road elongation and } \\
\text { the regularity of road } \\
\text { segments. Roads not easily } \\
\text { accessible, a higher proportion } \\
\text { of dead-ends (dangles) and } \\
\text { fewer intersecting nodes. }\end{array}$ & Spatial analysis in ArcGIS \\
\hline $\begin{array}{l}\text { Consistency of housing } \\
\text { orientation }\end{array}$ & Asymmetry & $\begin{array}{l}\text { This indicates simplicity of } \\
\text { shape. In the computer vision } \\
\text { literature, the angles and } \\
\text { lengths of line segments } \\
\text { exhibit greater angular } \\
\text { variability and shorter lengths } \\
\text { in informal settlements. }\end{array}$ & Object feature in eCognition \\
\hline Dwelling shape & Shape & $\begin{array}{l}\text { The relative length of an } \\
\text { image object, compared to a } \\
\text { regular polygon. }\end{array}$ & $\begin{array}{l}\text { Area of the segment/area of } \\
\text { the minimum bounding } \\
\text { rectangle of the segment. }\end{array}$ \\
\hline
\end{tabular}


Table A1. Cont.

\begin{tabular}{|c|c|c|c|}
\hline $\begin{array}{c}\text { Informal } \\
\text { Settlements/Variable }\end{array}$ & Parameters & Description & Equation/Tool \\
\hline $\begin{array}{l}\text { Building density (dwelling } \\
\text { separation) }\end{array}$ & Density & $\begin{array}{l}\text { Lower nearest-neighbour } \\
\text { distance using centroid of } \\
\text { dwelling polygons. Density is } \\
\text { calculated based on the image } \\
\text { object that contains the } \\
\text { current candidate pixel. This } \\
\text { allows the smoothing of the } \\
\text { border of the image object } \\
\text { without taking neighbouring } \\
\text { image objects into account. }\end{array}$ & Object feature in eCognition \\
\hline Proximity to hazards & $\begin{array}{l}\text { Digital elevation model } \\
\text { (DEM) }\end{array}$ & $\begin{array}{l}\text { Only flood hazards were } \\
\text { considered. }\end{array}$ & Spatial analysis in ArcGIS \\
\hline Geomorphology of terrain & $\begin{array}{l}\text { Digital elevation model } \\
\text { (DEM) }\end{array}$ & $\begin{array}{l}\text { Settlements built on relatively } \\
\text { flat surfaces. }\end{array}$ & Object feature in eCognition \\
\hline $\begin{array}{l}\text { Proximity to city centre and } \\
\text { social services }\end{array}$ & ProxToCent & $\begin{array}{l}\text { Network analysis of distance } \\
\text { to city services, market area or } \\
\text { city centre and healthcare } \\
\text { facilities. Greater distances } \\
\text { expected. }\end{array}$ & Spatial analysis in ArcGIS \\
\hline
\end{tabular}

\section{Appendix B}

Table A2. LandTrendr segmentation parameters used in this study as default values.

\begin{tabular}{|c|c|}
\hline Run_Name & Refpoints \\
\hline base_index & TCA, TCB, TCG, TCW \\
\hline background_val & 0 \\
\hline divisor & 1 \\
\hline minneeded & 6 \\
\hline kernelsize & 1 \\
\hline pval & 0.05 \\
\hline fix_doy_effect & 1 \\
\hline max_segments & 7 \\
\hline recovery_threshold & 1 \\
\hline skipfactor & 1 \\
\hline desawtooth_val & 1 \\
\hline distweightfactor & 2 \\
\hline vertexcountovershoot & 3 \\
\hline bestmodelproportion & 0.75 \\
\hline mask_image & na \\
\hline ulx & na \\
\hline uly & na \\
\hline $\operatorname{lr} x$ & na \\
\hline lry & na \\
\hline
\end{tabular}

\section{References}

1. Kuffer, M.; Pfeffer, K.; Sliuzas, R.; Baud, I. Extraction of Slum Areas from VHR Imagery Using GLCM Variance. IEEE J. Sel. Top. Appl. Earth Obs. Remote Sens. 2016, 9, 1830-1840. [CrossRef]

2. Mitchell, D.; Enemark, S.; van der Molen, P. Climate resilient urban development: Why responsible land governance is important. Land Use Policy 2015, 48, 190-198. [CrossRef]

3. Jones, P. Formalizing the Informal: Understanding the Position of Informal Settlements and Slums in Sustainable Urbanization Policies and Strategies in Bandung, Indonesia. Sustainability 2017, 9, 1436. [CrossRef]

4. Kuffer, M.; Pfeffer, K.; Sliuzas, R. Slums from Space-15 Years of Slum Mapping Using Remote Sensing. Remote Sens. 2016, 8, 455. [CrossRef] 
5. Abascal, A.; Rothwell, N.; Shonowo, A.; Thomson, D.; Elias, P.; Yeboah, G.; Kuffer, M. Domains of deprivation framework" for mapping slums, informal settlements, and other deprived areas in LMICs to improve urban planning and policy: A scoping review. Comput. Environ. Urban Syst. 2022, 93, 101770. [CrossRef]

6. UN-Habitat. Transforming Our World: The 2030 Agenda for Sustainable Development; UN-Habitat: New York, NY, USA, 2015.

7. United Nations. Slums of the World: The Face of Urban Poverty in the New Millennium; UN-Habitat: Nairobi, Kenya, 2003.

8. Chakraborty, A.; Wilson, B.; Sarraf, S.; Jana, A. Open data for informal settlements: Toward a user's guide for urban managers and planners. J. Urban Manag. 2015, 4, 74-91. [CrossRef]

9. Dadras, M.; Shafri, H.Z.M.; Ahmad, N.; Pradhan, B.; Safarpour, S. Spatio-temporal analysis of urban growth from remote sensing data in Bandar Abbas city, Iran. Egypt. J. Remote Sens. Space Sci. 2015, 18, 35-52. [CrossRef]

10. Belal, A.A.; Moghanm, F.S. Detecting urban growth using remote sensing and GIS techniques in Al Gharbiya governorate, Egypt. Egypt. J. Remote Sens. Space Sci. 2011, 14, 73-79. [CrossRef]

11. Mohamed, E.S.; Saleh, A.M.; Belal, A.A. Sustainability indicators for agricultural land use based on GIS spatial modeling in North of Sinai-Egypt. Egypt. J. Remote Sens. Space Sci. 2014, 17, 1-15. [CrossRef]

12. Song, X.-P.; Sexton, J.O.; Huang, C.; Channan, S.; Townshend, J.R. Characterizing the magnitude, timing and duration of urban growth from time series of Landsat-based estimates of impervious cover. Remote Sens. Environ. 2016, 175, 1-13. [CrossRef]

13. Lu, H.; Liu, C.; Li, N.; Fu, X.; Li, L. Optimal segmentation scale selection and evaluation of cultivated land objects based on high-resolution remote sensing images with spectral and texture features. Environ. Sci. Pollut. Res. 2021, 28, 27067-27083. [CrossRef]

14. Alganci, U.; Seker, D.Z.; Sertel, E.; Kaya, S. Spatio-temporal analysis of urbanization related land use/cover dynamics using satellite imagery: Case study antalya, Turkey. In Proceedings of the 33rd Asian Conference on Remote Sensing 2012, Melbourne, Australia, 25 August-1 September 2012; pp. 1111-1116.

15. Stoica, I.-V.; Zamfir, D.; Vîrghileanu, M. Evaluating the Territorial Impact of Built-Up Area Expansion in the Surroundings of Bucharest (Romania) through a Multilevel Approach Based on Landsat Satellite Imagery. Remote Sens. 2021, 13, 3969. [CrossRef]

16. Randazzo, G.; Italiano, F.; Micallef, A.; Tomasello, A.; Cassetti, F.P.; Zammit, A.; D’Amico, S.; Saliba, O.; Cascio, M.; Cavallaro, F.; et al. WebGIS Implementation for Dynamic Mapping and Visualization of Coastal Geospatial Data: A Case Study of BESS Project. Appl. Sci. 2021, 11, 8233. [CrossRef]

17. Healey, S.P.; Cohen, W.B.; Yang, Z.; Kenneth Brewer, C.; Brooks, E.B.; Gorelick, N.; Hernandez, A.J.; Huang, C.; Joseph Hughes, M.; Kennedy, R.E.; et al. Mapping forest change using stacked generalization: An ensemble approach. Remote Sens. Environ. 2018, 204, 717-728. [CrossRef]

18. Liu, T.; Yang, X. Monitoring land changes in an urban area using satellite imagery, GIS and landscape metrics. Appl. Geogr. 2015, 56, 42-54. [CrossRef]

19. Śleszyński, P.; Gibas, P.; Sudra, P. The Problem of Mismatch between the CORINE Land Cover Data Classification and the Development of Settlement in Poland. Remote Sens. 2020, 12, 2253. [CrossRef]

20. Durieux, L.; Lagabrielle, E.; Nelson, A. A method for monitoring building construction in urban sprawl areas using object-based analysis of Spot 5 images and existing GIS data. ISPRS J. Photogramm. Remote Sens. 2008, 63, 399-408. [CrossRef]

21. Hamedianfar, A.; Barakat, A.; Gibril, M. Large-scale urban mapping using integrated geographic object-based image analysis and artificial bee colony optimization from worldview-3 data. Int. J. Remote Sens. 2019, 40, 6796-6821. [CrossRef]

22. Wang, Y.; Li, M. Urban Impervious Surface Detection From Remote Sensing Images: A review of the methods and challenges. IEEE Geosci. Remote Sens. Mag. 2019, 7, 64-93. [CrossRef]

23. Kohli, D.; Sliuzas, R.; Stein, A. Urban slum detection using texture and spatial metrics derived from satellite imagery. J. Spat. Sci. 2016, 61, 405-426. [CrossRef]

24. Kohli, D.; Warwadekar, P.; Kerle, N.; Sliuzas, R.; Stein, A. Transferability of Object-Oriented Image Analysis Methods for Slum Identification. Remote Sens. 2013, 5, 4209. [CrossRef]

25. Fallatah, A.; Jones, S.; Mitchell, D.; Kohli, D. Mapping informal settlement indicators using object-oriented analysis in the Middle East. Int. J. Digit. Earth 2018, 12, 802-824. [CrossRef]

26. Hofmann, P.; Strobl, J.; Blaschke, T.; Kux, H. Detecting informal settlements from QuickBird data in Rio de Janeiro using an object based approach. In Object-Based Image Analysis: Spatial Concepts for Knowledge-Driven Remote Sensing Applications; Blaschke, T., Lang, S., Hay, G.J., Eds.; Springer: Berlin/Heidelberg, Germany, 2008; pp. 531-553.

27. Kuffer, M.; Wang, J.; Nagenborg, M.; Pfeffer, K.; Kohli, D.; Sliuzas, R.; Persello, C. The Scope of Earth-Observation to Improve the Consistency of the SDG Slum Indicator. ISPRS Int. J. Geo-Inf. 2018, 7, 428. [CrossRef]

28. Fallatah, A.; Jones, S.; Mitchell, D. Object-based random forest classification for informal settlements identification in the Middle East: Jeddah a case study. Int. J. Remote Sens. 2020, 41, 4421-4445. [CrossRef]

29. Chen, R.; Li, X.; Li, J. Object-Based Features for House Detection from RGB High-Resolution Images. Remote Sens. 2018, 10, 451. [CrossRef]

30. Salas, E.; Boykin, K.; Valdez, R. Multispectral and Texture Feature Application in Image-Object Analysis of Summer Vegetation in Eastern Tajikistan Pamirs. Remote Sens. 2016, 8, 78. [CrossRef]

31. Keshtkar, H.; Voigt, W.; Alizadeh, E. Land-cover classification and analysis of change using machine-learning classifiers and multi-temporal remote sensing imagery. Arab. J. Geosci. 2017, 10, 154. [CrossRef] 
32. Mellor, A.; Boukir, S.; Haywood, A.; Jones, S. Exploring issues of training data imbalance and mislabelling on random forest performance for large area land cover classification using the ensemble margin. ISPRS J. Photogramm. Remote Sens. 2015, 105, 155-168. [CrossRef]

33. Kooistra, L.; Kuilder, E.T.; Mücher, C.A. Object-based random forest classification for mapping floodplain vegetation structure from nation-wide CIR AND LiDAR datasets. In Proceedings of the 2014 6th Workshop on Hyperspectral Image and Signal Processing: Evolution in Remote Sensing (WHISPERS), Lausanne, Switzerland, 24-27 June 2014; pp. 1-4.

34. Förster, M.; Kleinschmit, B. Object-based classification of QuickBird data using ancillary information for the detection of forest types and NATURA 2000 habitats. In Object-Based Image Analysis: Spatial Concepts for Knowledge-Driven Remote Sensing Applications; Blaschke, T., Lang, S., Hay, G.J., Eds.; Springer: Berlin/Heidelberg, Germany, 2008; pp. 275-290.

35. Cohen, W.B.; Yang, Z.; Healey, S.P.; Kennedy, R.E.; Gorelick, N. A LandTrendr multispectral ensemble for forest disturbance detection. Remote Sens. Environ. 2018, 205, 131-140. [CrossRef]

36. Wulder, M.A.; Loveland, T.R.; Roy, D.P.; Crawford, C.J.; Masek, J.G.; Woodcock, C.E.; Allen, R.G.; Anderson, M.C.; Belward, A.S.; Cohen, W.B.; et al. Current status of Landsat program, science, and applications. Remote Sens. Environ. 2019, 225, 127-147. [CrossRef]

37. Hislop, S.; Jones, S.; Soto-Berelov, M.; Skidmore, A.; Haywood, A.; Nguyen, T.H. A fusion approach to forest disturbance mapping using time series ensemble techniques. Remote Sens. Environ. 2019, 221, 188-197. [CrossRef]

38. Kennedy, R.; Yang, Z.; Gorelick, N.; Braaten, J.; Cavalcante, L.; Cohen, W.; Healey, S. Implementation of the LandTrendr Algorithm on Google Earth Engine. Remote Sens. 2018, 10, 691. [CrossRef]

39. Zhu, Z.; Wulder, M.A.; Roy, D.P.; Woodcock, C.E.; Hansen, M.C.; Radeloff, V.C.; Healey, S.P.; Schaaf, C.; Hostert, P.; Strobl, P.; et al Benefits of the free and open Landsat data policy. Remote Sens. Environ. 2019, 224, 382-385. [CrossRef]

40. Cohen, W.B.; Yang, Z.; Kennedy, R. Detecting trends in forest disturbance and recovery using yearly Landsat time series: 2. TimeSync-Tools for calibration and validation. Remote Sens. Environ. 2010, 114, 2911-2924. [CrossRef]

41. Mboga, N.; Persello, C.; Bergado, J.R.; Stein, A. Detection of Informal Settlements from VHR Images Using Convolutional Neural Networks. Remote Sens. 2017, 9, 1106. [CrossRef]

42. Nguyen, H.T.; Soto-Berelov, M.; Jones, S.D.; Haywood, A.; Hislop, S. Mapping forest disturbance and recovery for forest dynamics over large areas using Landsat time-series remote sensing. In Proceedings of the SPIE Remote Sensing, Warsaw, Poland, 2 November 2017; p. 11.

43. Fu, P.; Weng, Q. A time series analysis of urbanization induced land use and land cover change and its impact on land surface temperature with Landsat imagery. Remote Sens. Environ. 2016, 175, 205-214. [CrossRef]

44. Vieira, M.A.; Formaggio, A.R.; Rennó, C.D.; Atzberger, C.; Aguiar, D.A.; Mello, M.P. Object Based Image Analysis and Data Mining applied to a remotely sensed Landsat time-series to map sugarcane over large areas. Remote Sens. Environ. 2012, 123, 553-562. [CrossRef]

45. Kohli, D.; Sliuzas, R.; Kerle, N.; Stein, A. An ontology of slums for image-based classification. Comput. Environ. Urban Syst. 2012, 36, 154-163. [CrossRef]

46. Owen, K.K.; Wong, D.W. An approach to differentiate informal settlements using spectral, texture, geomorphology and road accessibility metrics. Appl. Geogr. 2013, 38, 107-118. [CrossRef]

47. Kennedy, R.E.; Yang, Z.; Cohen, W.B. Detecting trends in forest disturbance and recovery using yearly Landsat time series: 1. LandTrendr-Temporal segmentation algorithms. Remote Sens. Environ. 2010, 114, 2897-2910. [CrossRef]

48. Braaten, J.; Cohen, W.; Yang, Z. LandsatLinkr. Available online: http:/ / doi.org/10.5281/zenodo.819474 (accessed on 30 May 2019).

49. Zhu, Z.; Woodcock, C.E. Object-based cloud and cloud shadow detection in Landsat imagery. Remote Sens. Environ. 2012, 118, 83-94. [CrossRef]

50. Haywood, A.; Verbesselt, J.; Baker, P. Mapping disturbance dynamics in wet sclerophyll forests using time series landsat. Int. Arch. Photogramm. Remote Sens. Spat. Inf. Sci. 2016, XLI-B8, 633-641. [CrossRef]

51. White, J.C.; Wulder, M.A.; Hobart, G.W.; Luther, J.E.; Hermosilla, T.; Griffiths, P.; Coops, N.C.; Hall, R.J.; Hostert, P.; Dyk, A.; et al. Pixel-Based Image Compositing for Large-Area Dense Time Series Applications and Science. Can. J. Remote Sens. 2014, 40, 192-212. [CrossRef]

52. Zhu, L.; Liu, X.; Wu, L.; Tang, Y.; Meng, Y. Long-Term Monitoring of Cropland Change near Dongting Lake, China, Using the LandTrendr Algorithm with Landsat Imagery. Remote Sens. 2019, 11, 1234. [CrossRef]

53. USGS. Available online: https://www.usgs.gov/ (accessed on 30 April 2019).

54. Barsi, J.; Schott, J.; Palluconi, F.; Hook, S. Validation of a Web-Based Atmospheric Correction Tool for Single Thermal Band Instruments; SPIE: Bellingham, WA, USA, 2005; Volume 5882.

55. Haywood, A.; Mellor, A.; Stone, C. A strategic forest inventory for public land in Victoria, Australia. For. Ecol. Manag. 2016, 367, 86-96. [CrossRef]

56. Crist, E.P. A TM Tasseled Cap equivalent transformation for reflectance factor data. Remote Sens. Environ. 1985, 17, 301-306. [CrossRef]

57. Vogeler, J.C.; Braaten, J.D.; Slesak, R.A.; Falkowski, M.J. Extracting the full value of the Landsat archive: Inter-sensor harmonization for the mapping of Minnesota forest canopy cover (1973-2015). Remote Sens. Environ. 2018, 209, 363-374. [CrossRef] 
58. Aguilar, M.A.; Vicente, R.; Aguilar, F.J.; Fernández, A.; Saldaña, M.M. Optimizing object-based classification in urban environments using very high resolution geoeye-1 imagery. ISPRS Ann. Photogramm. Remote Sens. Spat. Inf. Sci. 2012, I-7, 99-104. [CrossRef]

59. Benz, U.C.; Hofmann, P.; Willhauck, G.; Lingenfelder, I.; Heynen, M. Multi-resolution, object-oriented fuzzy analysis of remote sensing data for GIS-ready information. ISPRS J. Photogramm. Remote Sens. 2004, 58, 239-258. [CrossRef]

60. Hofmann, P.; Lettmayer, P.; Blaschke, T.; Belgiu, M.; Wegenkittl, S.; Graf, R.; Lampoltshammer, T.J.; Andrejchenko, V. Towards a framework for agent-based image analysis of remote-sensing data. Int. J. Image Data Fusion 2015, 6, 115-137. [CrossRef]

61. Nyandwi, E.; Koeva, M.; Kohli, D.; Bennett, R. Comparing Human versus Machine-Driven Cadastral Boundary Feature Extraction. Remote Sens. 2019, 11, 1662. [CrossRef]

62. Kuffer, M.; Sliuzas, R.; Pfeffer, K.; Baud, I. The utility of the co-occurrence matrix to extract slum areas from VHR imagery. In Proceedings of the 2015 Joint Urban Remote Sensing Event, Lausanne, Switzerland, 30 March-1 April 2015.

63. Haralick, R.M.; Shanmugam, K.; Dinstein, I. Textural Features for Image Classification. IEEE Trans. Syst. Man Cybern. 1973, SMC-3, 610-621. [CrossRef]

64. de Leeuw, J.; Jia, H.; Yang, L.; Liu, X.; Schmidt, K.; Skidmore, A.K. Comparing accuracy assessments to infer superiority of image classification methods. Int. J. Remote Sens. 2006, 27, 223-232. [CrossRef]

65. Breiman, L. Random Forests. Mach. Learn. 2001, 45, 5-32. [CrossRef]

66. Ghorbanzadeh, O.; Valizadeh Kamran, K.; Blaschke, T.; Aryal, J.; Naboureh, A.; Einali, J.; Bian, J. Spatial Prediction of Wildfire Susceptibility Using Field Survey GPS Data and Machine Learning Approaches. Fire 2019, 2, 43. [CrossRef]

67. Feng, Q.; Liu, J.; Gong, J. UAV Remote Sensing for Urban Vegetation Mapping Using Random Forest and Texture Analysis. Remote Sens. 2015, 7, 1074-1094. [CrossRef]

68. Yuan, Y.; Hu, X. Random forest and objected-based classification for forest pest extraction from uav aerial imagery. Int. Arch Photogramm. Remote Sens. Spat. Inf. Sci. 2016, XLI-B1, 1093-1098. [CrossRef]

69. Mahabir, R.; Croitoru, A.; Crooks, A.T.; Agouris, P.; Stefanidis, A. A Critical Review of High and Very High-Resolution Remote Sensing Approaches for Detecting and Mapping Slums: Trends, Challenges and Emerging Opportunities. Urban Sci. $2018,2,8$. [CrossRef]

70. Blaschke, T. Object based image analysis for remote sensing. ISPRS J. Photogramm. Remote Sens. 2010, 65, 2-16. [CrossRef]

71. Duro, D.C.; Franklin, S.E.; Dubé, M.G. A comparison of pixel-based and object-based image analysis with selected machine learning algorithms for the classification of agricultural landscapes using SPOT-5 HRG imagery. Remote Sens. Environ. 2012, 118, 259-272. [CrossRef]

72. Duque, J.C.; Patino, J.E.; Betancourt, A. Exploring the Potential of Machine Learning for Automatic Slum Identification from VHR Imagery. Remote Sens. 2017, 9, 895. [CrossRef]

73. Li, X.; Zhou, Y.; Zhu, Z.; Liang, L.; Yu, B.; Cao, W. Mapping annual urban dynamics (1985-2015) using time series of Landsat data. Remote Sens. Environ. 2018, 216, 674-683. [CrossRef]

74. Medhi, A.; Kumar Saha, A. Rural Road Extraction using Object Based Image Analysis (OBIA): A case study from Assam, India. Adv. Cartogr. GIScience ICA 2019, 1, 1-8. [CrossRef]

75. McFeeters, S.K. The use of the Normalized Difference Water Index (NDWI) in the delineation of open water features. Int. J. Remote Sens. 1996, 17, 1425-1432. [CrossRef]

76. Zhao, X.; Yu, B.; Liu, Y.; Chen, Z.; Li, Q.; Wang, C.; Wu, J. Estimation of Poverty Using Random Forest Regression with Multi-Source Data: A Case Study in Bangladesh. Remote Sens. 2019, 11, 375. [CrossRef]

77. Huang, B.; Zhao, B.; Song, Y. Urban land-use mapping using a deep convolutional neural network with high spatial resolution multispectral remote sensing imagery. Remote Sens. Environ. 2018, 214, 73-86. [CrossRef]

78. Fu, Y.; Li, J.; Weng, Q.; Zheng, Q.; Li, L.; Dai, S.; Guo, B. Characterizing the spatial pattern of annual urban growth by using time series Landsat imagery. Sci. Total Environ. 2019, 666, 274-284. [CrossRef] 